\title{
Personal strategies to minimise effects of air pollution on respiratory health: advice for providers, patients and the public
}

\author{
Christopher Carlsten ${ }^{1}$, Sundeep Salvi ${ }^{2}$, Gary W.K. Wong ${ }^{3}$ and Kian Fan Chung ${ }^{4}$ \\ Affiliations: ${ }^{1}$ Air Pollution Exposure Laboratory, Dept of Medicine, University of British Columbia, Vancouver, \\ BC, Canada. ${ }^{2}$ Chest Research Foundation, Pune, India. ${ }^{3}$ Dept of Pediatrics and School of Public Health, \\ Chinese University of Hong Kong, Shatin, Hong Kong. ${ }^{4}$ Faculty of Medicine, National Heart and Lung Institute, \\ Imperial College London, Royal Brompton and Harefield NHS Foundation Trust, London, UK.
}

Correspondence: Christopher Carlsten, Dept of Medicine, University of British Columbia, 2775 Laurel Street, Vancouver, BC V5Z 1M9, Canada. E-mail: christopher.carlstendubc.ca

@ERSpublications

This article draws on published literature and evidence to provide clear guidance on personal strategies that can help providers, patients and the public minimise daily exposure to air pollution in order to benefit respiratory health http://bit.ly/2Imbydp

Cite this article as: Carlsten C, Salvi S, Wong GWK, et al. Personal strategies to minimise effects of air pollution on respiratory health: advice for providers, patients and the public. Eur Respir J 2020; 55: 1902056 [https://doi.org/10.1183/13993003.02056-2019].

ABSTRACT As global awareness of air pollution rises, so does the imperative to provide evidence-based recommendations for strategies to mitigate its impact. While public policy has a central role in reducing air pollution, exposure can also be reduced by personal choices. Qualified evidence supports limiting physical exertion outdoors on high air pollution days and near air pollution sources, reducing nearroadway exposure while commuting, utilising air quality alert systems to plan activities, and wearing facemasks in prescribed circumstances. Other strategies include avoiding cooking with solid fuels, ventilating and isolating cooking areas, and using portable air cleaners fitted with high-efficiency particulate air filters. We detail recommendations to assist providers and public health officials when advising patients and the public regarding personal-level strategies to mitigate risk imposed by air pollution, while recognising that well-designed prospective studies are urgently needed to better establish and validate interventions that benefit respiratory health in this context.

This article has supplementary material available from erj.ersjournals.com

Received: 21 Oct 2019 | Accepted after revision: 24 Feb 2020

Copyright CERS 2020. This version is distributed under the terms of the Creative Commons Attribution NonCommercial Licence 4.0. 


\section{Introduction}

Air pollution and climate change were recognised as the top environmental global threats to human health in 2019 by the World Health Organization (WHO) [1]. A recent refined modelling indicates that prior prediction models have underestimated the health burden of air pollution and estimates there are currently approximately 9 million annual deaths from global air pollution [2] with $>99 \%$ of deaths due to household air pollution, and nearly $90 \%$ of deaths due to ambient air pollution occurring in low- and middle-income countries [3] where burning of solid fuels for cooking and heating is a major health concern [4]. Over $25 \%$ of premature deaths associated with air pollution were reported to be respiratory in nature [5] and we focus this review on respiratory health, knowing that minimising airway exposure generally protects also against cardiovascular effects (given that inhalation is the common portal of entry) [6-8]. Since there is no known level of air pollution exposure that is risk free, strategies to minimise daily exposure can be impactful across a wide range of settings and the nonlinear nature of the exposure-response curves for many health outcomes implies that the greatest benefits may occur when relatively low air pollution exposure levels are reduced even further $[2,9]$.

Urban planning must evolve so that concerns regarding air pollution become central to development (rather than an afterthought), and city centres must become practically designed so as to make living and working in close proximity attractive. This will avoid sprawl and make active transport more realistic. Such planning is critical. Other aspects of public policy play a primary role in source control and structural approaches to minimise exposure, and individuals should act as broadly as possible to reduce the root causes of fossil fuel dependence (through consumer choice, participation in the democratic process or other advocacy). Still, the impact of air pollution can also be reduced by personal choices. Therefore, the public must be empowered with strategies to minimise the effects of air pollution on respiratory health, but there remains an unmet need in providing education and support to communities around ways in which they can limit their exposure to the harmful levels of air pollution [10]. A report in 2016 by the Royal College of Physicians in the UK recommended that healthcare professionals (HCPs) should help vulnerable patients protect themselves from the effects of air pollution [11] and yet a subsequent workshop convened by the European Respiratory Society highlighted the lack of evidence-based tools available in this regard [10].

Accordingly, HCPs should be armed with up-to-date scientific evidence in order to prescribe impact-reducing tactics. This will allow HCPs to leverage their position as trusted messengers and embrace their responsibility to educate and advocate for preventive measures rather than simply reactive treatment. Our aim, therefore, is to provide recommendations for individuals to minimise their personal exposure to air pollution with advice that can be adapted to local needs in different countries, particularly when relevant to those who suffer from respiratory conditions, such as asthma and chronic obstructive pulmonary disease (COPD), or are at risk for these conditions. We designed a search strategy to uncover evidence surrounding $10 \mathrm{key}$ approaches for reduction of outdoor or indoor air pollution exposure, after which we detailed and finally summarised that evidence for the reader.

\section{Search strategy and selection criteria}

PubMed and Google Scholar were searched from January 1, 2013 to January 1, 2019 for search terms relating to air pollution, respiratory health, and strategies to minimise exposure to air pollution from ambient and household sources. The full list of the search terms and the resulting "hits" can be found in supplementary table S1. The flowchart of the literature review is shown in figure 1. Using that approach, we identified peer-reviewed scientific evidence that addressed the effectiveness of personal-level interventions to reduce exposure to air pollution, as well as the role therein of effect modifiers such as diet and lifestyle. Additionally, key knowledge gaps and research directions were identified to help clarify current uncertainties relating to air pollution exposure and health outcomes. The literature search was restricted to the 6 years up to 2019 in order to build on previous expert reviews and focus on the most up-to-date evidence. In order to assess the strength of the evidence, a level-of-evidence score was assigned to include clinical studies based on the grading used in the Global Initiative for Asthma (GINA) (supplementary table S2), inclusive of those scenarios in which recommendations are driven primarily by expert opinion rather than strong primary evidence [12].

\section{Minimising personal exposure to ambient air pollution}

Use facemasks under appropriate circumstances (evidence grade C)

Recommendations

- When anticipating unavoidable exposure to ambient air pollution exceeding recommended levels, consider close-fitting N95 facemasks after becoming informed about their limitations and pitfalls. 


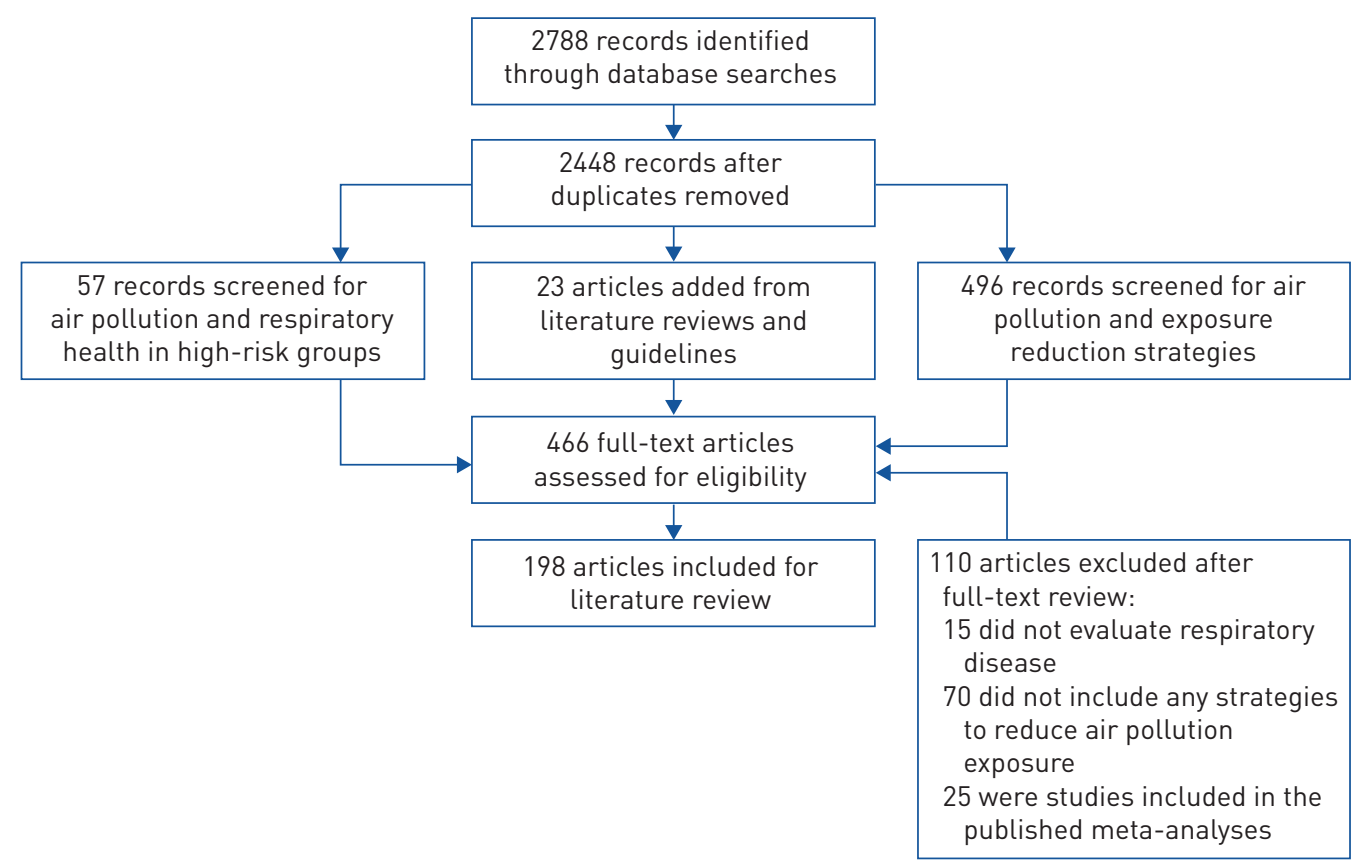

FIGURE 1 Flowchart of the literature review.

- When using a facemask, follow manufacturers' guidance on correct mask usage, maintenance and fit, including a user seal check [13].

- People with chronic respiratory, cardiac or other conditions that make breathing difficult should check with their healthcare provider before using an N95 facemask [14].

\section{Background and evidence}

Use of filtering facemasks to reduce inhalation of high air pollution levels is becoming more commonplace and socially acceptable around the world, particularly in Asia [15], but effectiveness varies according to the type of mask and filter, type of pollutant, and conditions of use [16]. Furthermore, filters are designed to remove particles and require additional absorbing features such as activated charcoal to efficiently remove gases $[13,16,17]$, which are inconsistently effective and come at an increased cost.

Mask effectiveness is related to filter quality and coverage, number of different filter layers, how well the mask fits to the face, and the size of incoming particles (N95 effectiveness drops considerably within the ultrafine range) [18]. Facial hair [14], facial structure and movement have a large impact on the actual protection conferred, even if the laboratory-based filtration efficacy is high [19]. To measure the effectiveness of facemasks, a study in Beijing in China measured the amount of black carbon inside a mask, expressed as a percentage of the black carbon concentration outside of the mask (in an exposure chamber), to determine the average total inward leakage of black carbon; this ranged from $3 \%$ to $68 \%$ dependent on mask design and fit [19]. Furthermore, user comfort and acceptability are important for mask effectiveness [16], but are not routinely tested or uniformly certified in the consumer context. Users who, based on age [14] or ethnicity [20], are outside of the typical testing prototype may have particular challenges.

Masks can trap warm, moist air, leading to rashes or overheating [21] and potentially pathogen retention [22]. Additionally, respirators may increase resistance to breathing, which may contribute to potential cardiovascular effects [16, 23, 24]. Cloth masks, which are inexpensive and used commonly in underdeveloped regions, remove only $15 \%$ of particles of size typical of diesel engine emissions [25] and are far inferior to protection against fine particles than facemasks rated as N95 (defined as filtering $\geqslant 95 \%$ of $0.3 \mu \mathrm{m}$ particles under test conditions) $[13,14,25]$.

Disposable surgical masks appear more effective than cloth or "bandana-style" masks [26, 27]. However, the design of surgical masks confers poor facial fit [14] and often high inward leakage during actual use [19]. Facemasks may even confer on users a false sense of security and an assumption of protection that can detract from primary air pollution avoidance efforts [25].

Evidence that N95 facemask use has an impact on cardiopulmonary health is limited. Short-term (2 h) use reduced particle-associated airway inflammation [24] and improved measures of autonomic nervous 
function $[8,28]$ and blood pressure [8] versus wearing no facemask. N95 facemask use reduced the decline in lung function associated with air pollution among traffic police in Nepal [27]. In a small, randomised, crossover study, powered air-purifying respirators with high-efficiency particulate air (HEPA) filters (likely impractical for most users) reduced exhaled markers of oxidative stress in individuals in cars within heavy traffic versus without HEPA filters [29], although another study using a standard N95 facemask showed no protection from systemic oxidative stress [24].

With technical improvements (e.g. using nanofibre technologies, metal-organic coatings and antimicrobial features, and the use of three-dimensional printing for better fitting personal facemasks), facemasks may provide better filtration and comfort [30-33]. However, each such innovation requires rigorous testing to ensure effectiveness.

\section{Shift from motorised to active transport whenever possible (evidence grade C) Recommendations}

- A shift from motorised to active transport (cycling or walking) should be encouraged.

- Infrastructure should be designed to prioritise active transportation and make age-appropriate accommodations.

\section{Background and evidence}

High exposures to traffic-related air pollution (TRAP) can occur inside vehicles due to the proximity of air intake of exhaust emissions from neighbouring vehicles as well as while walking or cycling alongside roads [34]. Comparing air pollution exposures related to active versus motorised travel modes found the highest exposures for air pollutants such as particles with a 50\% cut-off aerodynamic diameter $<2.5 \mu \mathrm{m}\left(\mathrm{PM}_{2.5}\right)$, black carbon and ultrafine particles (UFPs) were in car drivers and the lowest exposures were in cyclists or pedestrians [35, 36], although other studies have reported conflicting results [37-39]. Proximity to motorised traffic was associated with high cyclist and pedestrian exposure concentrations [40, 41], particularly when cycling along roads shared with motor vehicles [37, 42].

Cyclists, followed by pedestrians, have the highest level of inhalation and uptake dose of air pollutants (owing to their close proximity to traffic, increased respiration rates and longer journeys) while the lowest are in train, metro and subway commuters, and motorcyclists [43-45]. However, the benefits of physical activity when actively commuting versus using motorised transport appear to outweigh the risks associated with the increased inhaled dose of air pollutants [43, 46-48] and a protective effect of physical activity with respect to mortality even in high air pollution environments has been reported $[49,50]$.

Walking along a traffic-polluted road curtails or even reverses the cardiorespiratory benefits of exercise in older individuals and in adults with chronic cardiorespiratory disorders [51]. However, older people may be more vulnerable to traffic incidents while walking or cycling than younger people [47].

A shift from car and public transport use to active transport (cycling or walking) has been advocated [52, 53] with benefits derived from a reduction in traffic volume and related air pollution emissions leading to overall health benefits [54] in spite of minor reductions in lung function in some contexts [55].

\section{Choose travel routes that minimise near-road air pollution exposure (evidence grade C) Recommendations}

- Avoid major intersections, queuing traffic, heavily trafficked roads and higher-emission sides of a given road.

- Select routes with open spaces and/or greater heterogeneity in building morphology to facilitate dispersal of air pollutants.

- Use designated off-road cycle tracks versus on-road bicycle paths.

- Use up-to-date real-time information on local air quality, such as mobile phone applications, news feeds and websites, to guide route and timing.

\section{Background and evidence}

TRAP levels decline steeply with increasing distance from motorised vehicles [16, 41], with up to 10 times lower concentrations of black carbon when $10 \mathrm{~m}$ away from traffic roads [56]. Therefore, increasing the distance between pedestrians and cyclists from vehicle emissions is a fundamental aim. Even crossing to the less polluted side of a given same road can lead to a reduction of $18 \%$ of exposure to $\mathrm{PM}_{2.5}[57,58]$.

The highest particle number concentrations are found at the most congested and highly built-up parts of a route such as at traffic intersections [59], with levels 29 times higher than those found during free-flowing 
traffic conditions [60]. Pedestrian and cyclist exposure at traffic intersections was higher than on roads with free-flowing traffic $[56,61,62]$. Repeated vehicle accelerations and decelerations at intersections also increase in-vehicle TRAP exposure [63]. In contrast, roads in urban areas with open space and heterogeneous building morphology had around 2-3-fold lower concentrations of traffic emissions [61]. Therefore, choice of commuting routes and shifting active travel by cycling from a high-traffic road to an adjacent low-traffic road would lead to lesser exposure [41, 61, 62, 64, 65].

Bike paths or routes separated from motor traffic lanes had lower levels of air pollutants [66, 67]. The use of designated off-road cycle tracks versus on-road bicycle paths reduced cyclist exposure to air pollutants [43, 67-69], and use of sidewalks and off-road bicycle lanes separated by 7 and $19 \mathrm{~m}$ from the roadways resulted in significantly lower exposure than on the road [69]. The use of designated off-road footpaths and cycle tracks may be considered in community-level interventions (figure 2). Many of these routes may be associated with green space, which appears to provide mental health, metabolomic and cardiovascular benefit, but may unfortunately confer risk to respiratory health [73].

Children are, by their shorter stature, closer to the source of air pollution and have a faster respiratory rate which results in their exposure to black carbon being disproportionately high, particularly in association with transit to and from school, and at school [74]. Children's exposure can be reduced by avoiding major intersections, busy roads and queuing traffic where possible, and walking on the least trafficked side of the road [58]. Walking on the downhill side of the road (relative to traffic flow) may also help since driving uphill induces engine load, which increases emissions [75].

\section{OPTIMISE LAND USE AND ACCESS TO GREEN AREAS}

Land-use decisions tend not to consider air pollution-related health impacts nor do they require minimum distances between sources and individuals. Consequently, residential developments and key community resources (e.g. schools and hospitals) are often located near major traffic arteries [70].

Urban planning of "smart" cities must also balance the relative benefits and hazards of active travel with increased urban density and TRAP exposure [52].

Minimising the spread of urban developments to decrease dependence on motorised vehicles must be evaluated in the context of increasing urban density and ensuring active travel routes are not located in close proximity to high-traffic streets $[41,70]$
The result is that the primary sources of TRAP and the populations with increased susceptibility to air pollution health effects are often co-located [70].

Designated walking and cycling paths much be separated from motorised traffic where possible to reduce TRAP exposures and promote safety for active commuters [41].

A paper by the National Institute for Health and Care Excellence on the prioritised quality improvement areas for development relating to air pollution and health stated that a key area involved improving the relationship between land-use planning and transport planning, providing clear spatial principles which direct new development to locations which reduce the need for individual motorised travel, tackle congestion and improve air quality [52].
City planning should aim to promote physical separation of susceptible subpopulations from air pollution sources by incorporating community susceptibility profiles as well as knowledge of air pollution exposure sources such as bus and railway stations, transit corridors, and industrial areas [70].

Rethinking land use could reduce air pollution exposures for particularly susceptible populations [70].

Urban green space, such as parks, playgrounds and residential greenery, may promote mental and physical health as well as reduce respiratory morbidity and mortality in residents of urban areas by both reducing exposure to air pollutants and supporting physical activity $[71,72]$.

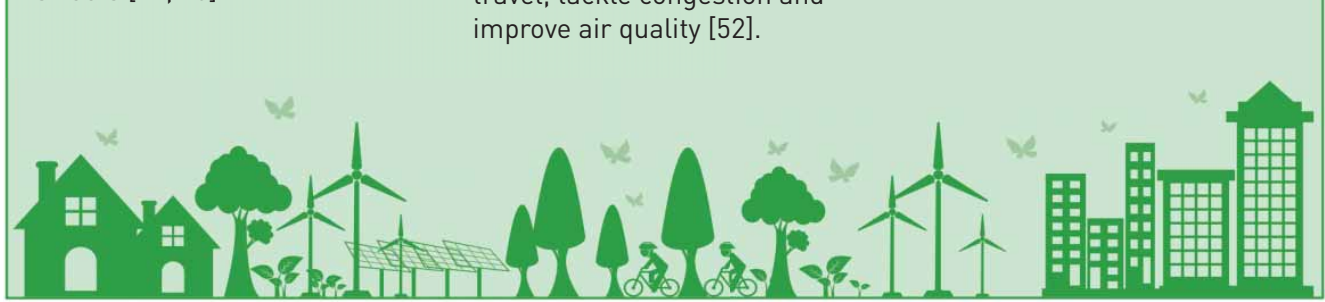

FIGURE 2 Community-level interventions. TRAP: traffic-related air pollution. 
Optimise driving style and vehicle settings (evidence grade D)

Recommendations

- Optimise and maintain vehicle filtration/ventilation and, when in conditions of high air pollution, drive with windows closed and keep the air on internal circulation.

- Avoid rapid accelerations and decelerations, restrict engine idling, and correctly maintain vehicles.

\section{Background and evidence}

As a society, we should promote incentives to move away from fossil fuel combustion, support alternative energy sources and associated infrastructure such as charging stations, and encourage development of nonpolluting materials for brakes and tyres. However, individuals who use personal vehicles for travel (even if they themselves use vehicles with noncombusting technology, such as electric vehicles) are exposed to levels of air pollution dependent on ventilation parameters, the ventilation system, and natural leakage from door seals and window cracks of the vehicle [16]. Car-cabin pollutant levels are similar to outdoor concentrations of particulate matter and carbon monoxide (CO) levels when windows are open [76]. While in traffic, opening car windows increased in-car cabin black carbon and UFP concentrations by 2-4-fold versus driving with windows closed [40, 77, 78] and in buses, by 3-fold [79]. Driving with windows closed was found to reduce traffic-related $\mathrm{PM}_{2.5}$ exposure by around 3-fold versus windows open [37].

Physical barriers such as controlled ventilation settings in cars help to extract and filter fine and coarse particles from the vehicle microenvironment [43]. Driving personal vehicles with windows closed and with air conditioning set to the "recirculate" setting reduced in-vehicle particle concentrations by up to $75 \%$ versus driving with windows open [68] and $\mathrm{PM}_{2.5}$ exposure levels were reduced by approximately $40 \%$ [80]. Using a fan set to recirculation versus external circulation mode while in traffic reduces TRAP exposures [76, 81], with one study showing UFP exposure reduction of up to $20 \%$ by recirculation through a HEPA filter [82].

Driving patterns such as frequent accelerations and idling influence vehicles emissions [76]. Frequent idling of vehicles was associated with high pollutant exposure for commuters using ground motorised transport on over-congested routes [43], while increasing levels of outdoor air pollutants [83], increasing in-vehicle exposures to air pollutants such as UFPs and black carbon [84], and increasing in-car volatile organic compound concentrations 1.3-5.0-fold compared with when the engine was off [85]. Idling prohibition or anti-idling campaigns near schools have shown significant reduction in particulate matter and harmful pollutants around schools $[83,86]$.

Older vehicles tend to generate higher emissions due to deterioration of vehicle control systems [87], incomplete combustion of fuel and oil, abrasion and wear of tyres and metallic components [88], and more permissive emission standards than newer vehicles.

\section{Moderate outdoor physical activity when and where air pollution levels are high (evidence grade C) Recommendations}

- Regular physical activity is generally beneficial except in conditions of extreme air pollution (especially for those with significant susceptibility such as cardiopulmonary disease).

- When exercising, do so away from traffic whenever possible, follow local air quality forecasts and plan outdoor activities around them.

- Decrease or stop exercising when noticing concerning symptoms such as coughing, chest tightness or wheezing.

\section{Background and evidence}

Outdoor activity and exercise could increase the impact of air pollution on respiratory health due to increased inhaled dose of air pollutants and to bypassing the nasal filtration defences [89]. Strenuous exercise may impair nasal mucociliary clearance and reduce nasal cilia beat frequency, leading to an increase in air pollution exposure [89], which can contribute to respiratory symptoms such as coughing, wheezing and breathlessness [90].

Still, physical activity might protect against the negative effects of TRAP on lung function in healthy adults [91-93]. One study suggested a threshold to negative effects on lung function at modest particulate matter levels [94]. However, intermittent moderate physical activity increased pulmonary function at low $\left(\mathrm{PM}_{2.5}\right.$ $\left.30 \mu \mathrm{g} \cdot \mathrm{m}^{-3}\right)$ and high $\left(\mathrm{PM}_{2.5} 81 \mu \mathrm{g} \cdot \mathrm{m}^{-3}\right)$ TRAP levels [91], and the adverse effects on lung function markers were negated by physical activity at low $\left(\mathrm{PM}_{2.5} 39 \mu \mathrm{g} \cdot \mathrm{m}^{-3}\right)$ and high $\left(\mathrm{PM}_{2.5} 82 \mu \mathrm{g} \cdot \mathrm{m}^{-3}\right)$ TRAP levels [93].

Overall, the optimal level of physical activity or threshold at which it can be protective against air pollution-related health risks is not known and likely to vary across age and health/disease status [89], and individuals with pre-existing conditions and children are particularly sensitive to air pollution exposure 
[89]. Older adults with COPD who walked on a traffic-polluted road in London in the UK for $2 \mathrm{~h}$ were found to have more cough, sputum, shortness of breath and wheeze versus walking in a traffic-free area [51]. Attenuation of the beneficial effects of physical activity on respiratory/pulmonary measures in healthy adults and those with chronic cardiorespiratory disorders when exposed to high versus low air pollution concentrations was noted [51]. The negative effect of $\mathrm{PM}_{2.5}$ on lung function was greater among Korean adults with suspected COPD or asthma who did not exercise versus those that did [95]. Regular exercise was associated with lower markers of systemic inflammation (white blood cell counts) than inactivity at different levels of $\mathrm{PM}_{2.5}$ exposure in Taiwan [96]. The beneficial health effects of regular physical activity on overall mortality were not moderated by long-term exposure to urban levels of air pollution, although cycling in areas with high air pollution versus moderate or low levels reduced the benefits of physical activity on respiratory mortality [49]. Increased exposure to nitrogen dioxide $\left(\mathrm{NO}_{2}\right)$ did not outweigh the beneficial effects of exercise for reducing risk of hospitalisation for asthma and COPD [97]. Therefore, even patients with pre-existing cardiorespiratory disease may experience neutral or beneficial effects of physical activities outdoors, including during periods of elevated air pollution, but may need to decrease intensity of exertion in proportion to severity of air pollution levels.

Those at risk can reduce their exposure to air pollutants by staying indoors on high pollution days and limiting outdoor physical activity near sources of air pollution [16, 89, 90, 98], consistent with recommended World Air Quality Index (AQI) value actions and US Environmental Protection Agency (EPA) standards (supplementary figure S1) [99, 100].

In the USA, air pollution was associated with reduced leisure-time physical activity and increased risk for physical inactivity $[101,102]$, as well as a self-reported reduction in outdoor activities [103]. In China, participation in outdoor exercise was impeded by air pollution severity [104], although better AQI levels and lower concentrations of fine particulate matter were associated with approximately 20 and 45 min reduction in sedentary time, respectively [105].

To minimise the respiratory health effects of air pollution, local governments often issue alerts on days when air pollution levels are forecast to be high, urging individuals at risk to stay indoors on such days. There is evidence to suggest that some people modify their outdoor activity when alerts are issued, especially those individuals with known susceptibility $[16,106,107]$, and this seems reasonable as a matter of caution (particularly when curtailing activity is only temporary, so that the long-term benefits of exercise are not lost).

\section{Monitor air pollution levels (evidence grade D) Recommendations}

- HCPs should encourage patients to be aware of the local air quality, and teach them how to check the air quality forecast and act to minimise air pollution exposure.

- Patients, especially those with underlying susceptibility, should be aware of air quality alerts and learn to implement appropriate protective behaviour on high air pollution days.

- If using a personal pollution monitor, users need to be aware that accuracy of such monitors is highly variable and that government-sponsored pollution monitors remain the standard for accuracy.

\section{Background and evidence}

Air pollution monitoring networks around the world that report real-time, local levels of ambient air pollution can provide information on when and where air pollutant levels are elevated above levels thought to confer increased risk [16]. For easy understanding by the general public, most authorities convert increasing concentrations of major air pollutants $\left(\mathrm{PM}_{2.5}\right.$, particles with a $50 \%$ cut-off aerodynamic diameter $<10 \mu \mathrm{m}\left(\mathrm{PM}_{10}\right)$, ozone, $\mathrm{CO}, \mathrm{NO}_{2}$ and sulphur dioxide $\left.\left(\mathrm{SO}_{2}\right)\right)$ into a single value indicating the relative quality of the ambient air and use severity bands to indicate progressive degrees of risk to health [108] as exemplified by the US EPA and World AQI scales (supplementary figure S1) [99, 100].

AQI scales may not be directly comparable between countries [108] due to differing air quality standards and use of different air pollutant cut-offs to define the severity bands [109-111]. Many AQIs calculate air quality according to the concentration of the highest individual pollutant at that time [112], not recognising the combined impacts of multiple pollutants, and thus may underestimate the associated health risks [109, 111, 113].

Air quality health indices (AQHIs) use the relative health risks of a combination of pollutants to determine the final index $[109,112,113]$. An AQHI based on the short-term associations of $\mathrm{SO}_{2}, \mathrm{NO}_{2}$, ozone and $\mathrm{PM}_{2.5}$ with mortality in China demonstrated greater correlation with health effects than current 
AQI systems [113]. When compared with AQHIs, the US EPA AQI underestimated the health effects of air pollution on high pollution days in China by at least one category of severity [109].

Regardless, AQIs may enhance public awareness of air pollution levels and encourage protective behaviours during periods of high air pollution $[109,110,112,113]$, particularly among high-risk individuals [111]. Real-time maps can provide the short-term health risk based on current pollution levels and some AQIs provide automated alerts to limit prolonged or heavy exertion outdoors when air pollution levels are high [114]. AQIs can be used to generate longer-term "risk maps" to estimate patients' chronic air pollution exposure at their homes and workplaces [115], and can help patients avoid high air pollution routes [116].

However, evidence is limited for AQI alerts facilitating exposure-minimising behaviour. Daily text messaging regarding air quality, air pollution risk communication and self-care increased behaviours to reduce exposure to outdoor air pollutants versus standard of care in pregnant women [106, 107]. In contrast, adherence to health advice accompanying AQI alerts in another study was suboptimal [117]. Furthermore, receiving information from an HCP significantly increased knowledge of the AQI for individuals with respiratory disease versus no information, but did not affect behaviour modification in response to index values [118].

Wearable sensors/monitors integrated into different mobile or electronic devices (including Global Positioning System-enabled models) [119-121] may be a cost-effective way to determine air pollution levels and potential risk at the individual level [122, 123]. A software program using smartphone technology coupled with predictive environmental air pollution models provided personal exposures to air pollution and calculated health risks [124]. Affordable access to such devices (and associated data) can lend a sense of empowerment that may motivate protective behaviour [125]. Estimation of inhaled dose could be incorporated with other fitness monitors such as wrist-worn heart rate trackers [122]. Such technologies could be used to inform clinician decisions about risk modification, and provide alerts to HCPs and carers for susceptible individuals when intervention is required [120]. Commercialised real-time particle monitors may help monitor household air pollution [126], but sensitivity remains limited [127]. Further limitations of low-cost personal sensors include loss of accuracy due to age [128], temperature and humidity changes [119], sensor drifts requiring frequent recalibration, and cross-sensitivities with other ambient air pollutants [128].

Most importantly, studies assessing the ability of air pollution sensors to induce exposure-minimising behaviour are limited [120-123]. While use of portable pollution sensors generated greater awareness of urban air pollution than traditional information sources, air pollution-reducing behaviour change did not follow [129], underscoring the current gap between empowering patients and true benefit to health therein.

Minimising personal exposure to household air pollution

Use clean fuels (evidence grade $\mathrm{C}$ ), optimise household ventilation (evidence grade $\mathrm{C}$ ) and adopt efficient cookstoves where possible (evidence grade D)

Recommendations

- In homes that use biomass fuel (wood, animal dung and crop residues) or coal for cooking and heating, substitute these with cleaner fuels such as biogas (methane), liquid petroleum gas (LPG), electricity or solar cookers when feasible.

- Ensure cooking areas, and all areas in the vicinity of burning mosquito coils, are well ventilated with cross-ventilation (opening windows or doors), chimneys or exhaust fans.

- After prioritising the adoption of cleaner fuels and better ventilation, switch to more efficient cookstoves if resources remain sufficient.

\section{Background and evidence}

Cleaner cooking fuels

Over 3 billion people worldwide use traditional cookstoves that burn wood, animal dung or crop residues to cook food or heat water [130]. This produces very high levels of indoor air pollution (such as CO and particulate matter) because of poor combustion efficiency [130]. Replacing biomass fuels with cleaner cooking fuels (LPG or electricity) reduced the risk of acute respiratory infection in children $<5$ years of age [131], was associated with shorter hospital stays for acute respiratory infections [132], lowered the risk of all-cause mortality versus persistent solid fuel users [133], and combined with improved kitchen ventilation reduced decline of lung function and COPD incidence [134]. Replacing solid fuels for cooking with cleaner fuels also reduced respiratory symptoms in women [135], and the incidence of bronchitis, phlegm and chest illness in women and children [136]. 
Improved ventilation

In some cultures, where weather permits, cooking is often conducted outdoors in well ventilated spaces and, when compared with indoor cooking, can reduce the prevalence of acute respiratory infection in children aged $<5$ years $[137,138]$. Among those who cook indoors, improving ventilation reduced the levels of CO and particulate matter $[139,140]$, and was associated with improved health outcomes, such as reduction in respiratory symptoms [141-143], reduced risk of asthma and prevalence of asthma-related symptoms among children [144, 145], reduced risk of lung cancer [146, 147], COPD incidence and pneumonia [147], and improved respiratory health-related quality of life in women [140].

Burning mosquito coils is another major source of household air pollution in tropical countries; mosquito coils are typically used indoors with door and windows closed to prevent mosquitoes from entering the home [148]. When burning a mosquito coil indoors, opening a window can reduce $\mathrm{PM}_{2.5}$ levels from 2200 to around $350 \mu \mathrm{g} \cdot \mathrm{m}^{-3}$; opening a window and door can further reduce levels to $70 \mu \mathrm{g} \cdot \mathrm{m}^{-3}$ [148].

Household ventilation can be improved by ensuring cross-ventilation via windows and doors, or by using chimneys, flues, hoods or exhaust fans [115]. While our recommendations are focused on combustion-related air pollution, ventilation may also serve to decrease the impact of chemicals in the home (e.g. from cleaning products and off-gassing from carpets and furniture), although a recent review suggests that indoor volatile organic compounds are attenuated more by time than by ventilation [149].

\section{Improved cookstoves}

Traditional cookstoves are often made up of stone, mud or clay [150] and burn solid fuels inefficiently [130]. There have been several attempts to build more efficient cookstoves by engineering design and/or incorporating a fan to improve combustion $[151,152]$, and in laboratory settings can reduce emissions by up to $90 \%$ [152]. However, field studies have indicated that although improved cookstoves can reduce $\mathrm{PM}_{2.5}$ levels significantly versus traditional cookstoves, they are not improved enough to achieve WHO-recommended $\mathrm{PM}_{2.5}$ levels [153].

Despite recommendations to use improved cookstoves by the WHO and the Global Initiative for Chronic Obstructive Lung Disease (GOLD) [154, 155], evidence for respiratory health benefits reported with use of improved cookstoves is minimal $[132,156,157]$. Accordingly, studies with improved cookstoves have not shown significant benefit in terms of improving quality of life among asthmatic children [158], improving lung function indices versus cooking over an open fire $[159,160]$ or reducing the risk of pneumonia in young children [152]. Adoption practices are sometimes incomplete [154, 161] due to efficacy as well as cultural reasons, suggesting a need for further education and training to sustain adherence and understand limitations [138, 141, 153]. The current level of evidence does not yet support the use of improved cookstoves, which may need to be combined with other air pollution reduction interventions to yield beneficial health effects $[162,163]$, but they may reasonably be adopted nonetheless as a common sense measure, when resources permit.

\section{Use portable air cleaners as an indoor environmental intervention (evidence grade C)} Recommendations

- Use portable HEPA-fitted air cleaners in the most frequented rooms of the home to help reduce respiratory health effects among the general population who face regular exposure to household air pollution and/or those with intermittent high-level particulate exposure.

- Avoid air-cleaning technologies that may emit harmful byproducts, including ionisers or ion generators that generate ozone.

- Place air cleaners where the most vulnerable occupants spend most of their time, without obstruction from furnishings.

- Regularly maintain air cleaners by following manufacturers' guidance.

\section{Background and evidence}

The use of portable air cleaners can lower indoor air pollution from cooking, cigarettes and other sources as well as outdoor pollution that infiltrates indoors, and these may provide an additional benefit by reducing volatile organic compounds associated with household chemicals [164]. Air filters such as HEPA filters capture particles on fibrous materials, while electronic air cleaners such as ionisers or electrostatic precipitators rely on electrostatic forces to remove airborne particles. Some air filters include adsorbent media such as activated carbon to remove gaseous air pollutants or convert them to harmless byproducts [165].

Efficiency of a portable air cleaner is reported as the minimum efficiency reporting value (MERV: ranging from 1 to 16). Effectiveness of portable air cleaners is described by the clean air delivery rate, which is 
expressed in cubic feet per minute. The higher the clean air delivery rate, the larger the area the cleaner can serve [165].

The use of HEPA filtration (typically equivalent to MERV 16) in living rooms and/or bedrooms has been shown to reduce indoor residential $\mathrm{PM}_{2.5}$ concentrations between $40 \%$ and $72 \%$ versus baseline, control or outdoor levels [166-170]. The efficiency of these filters to reduce $\mathrm{PM}_{2.5}$ has been shown to decrease over time [171].

HEPA filtration was also found to be effective in lowering indoor particulate matter resulting from wildfire emissions [171]. Modelling studies estimated that portable air cleaner use during wildfires in California in the USA provided mortality-related cost-effective benefits, which would be improved further by targeting the elderly [172]. Another modelling study came to similar conclusions for using activated carbon filters in homes to reduce indoor ozone of outdoor origin [173]. Public health officials in both the USA [174] and Canada [175] support the use of portable air cleaners to reduce exposure to wildfire smoke inside homes.

In terms of respiratory health benefits, several interventions studies have found portable air cleaners in homes to improve outcomes [176]. A small-scale intervention study suggested cardiopulmonary benefits (indicated by markers of airway inflammation, lung function and blood pressure) of air filter use in dormitories for $48 \mathrm{~h}$ among young, healthy adults in a Chinese city with severe ambient particulate air pollution [177]. In a study of children and adults in Shanghai in China, a single overnight HEPA-based filtration, along with activated carbon, reduced indoor $\mathrm{PM}_{2.5}$ concentrations and led to improved airway mechanics (airway impedance, airway resistance and small airway resistance) [166]. In a randomised intervention study, HEPA cleaners in the home reduced $\mathrm{PM}_{2.5}$ and improved asthma symptoms in children [178]. Among children for whom the air cleaner reduced indoor particulate matter concentrations, there was a large increase in symptom-free days [179] and improvement in asthma symptoms [180]. HEPA filters were also found to improve symptoms in patients with allergic rhinitis [181].

Few studies have investigated the benefit of adding activated carbon within a HEPA-based cleaner to reduce gaseous pollutant concentrations, but efficacy appears poor, with one study having demonstrated $\mathrm{NO}_{2}$ concentration reductions of approximately $20 \%$ versus baseline, with diminishing benefit over time [182]. Studies assessing whether gas-phase filtration or ionisers in air cleaners have a positive effect on human health are also scarce. A small study investigated the use of HEPA filter air cleaners with activated carbon in the living room and bedroom for 12 weeks and, while $\mathrm{PM}_{2.5}$ levels were reduced by $43 \%$ and there was a significant improvement in peak exploratory flow (suggestive of improved asthma control) attributable to the cleaner, there was no evidence that the activated carbon was itself effective [169].

\section{Effect modifiers: interventions to modify individual risk factors \\ Treat and manage respiratory conditions (evidence grade D) \\ Recommendations}

- Maximise control of airway disease through optimised care (e.g. symptom and airflow monitoring, medications, and vaccinations).

- Promote primary, secondary and tertiary interventions (e.g. reducing obesity, promoting physical activity, smoking cessation and avoidance of second-hand smoke) that may attenuate the burden of cardiopulmonary disease associated with air pollution exposure.

\section{Background and evidence}

Chronic respiratory conditions such as asthma and COPD may make individuals more susceptible to the adverse health effects associated with exposure to air pollution. Consensus recommendations for managing COPD include limiting exposure to ambient and household air pollution, as also indicated in the GINA strategy for asthma management and prevention $[12,155]$.

Optimising an individual's level of asthma control may influence respiratory response to in-vehicle exposures during rush-hour commuting, with one study in the USA showing that the largest post-commute increases in exhaled nitric oxide occurred in participants with below-median asthma control, and higher $\mathrm{PM}_{2.5}$ was associated with a lower forced expiratory volume in $1 \mathrm{~s}$ percentage predicted in this group [183]. Among Japanese children with asthma, exacerbation of respiratory signs and symptoms (percentage maximum peak expiratory flow and coughing) associated with oxidant exposure from ambient air pollution appeared greater in those who were not using long-term medications than those who were [184].

There is limited evidence for benefit of inhaled steroids for those with asthma faced with air pollution [185]. In a study of children with asthma, those not using corticosteroid medications experienced the greatest increase in fractional exhaled nitric oxide per interquartile range increase of $\mathrm{PM}_{2.5}$ oxidative 
burden [186]. However, there is not a clear dose-response relationship (higher dose of inhaled steroids does not appear to be associated with greater benefit) and caution about the long-term effectiveness of inhaled steroids to mitigate effects of air pollution have been raised [185]. Furthermore, an analysis of effect modification by daily use of asthma controller medications on airway responsiveness in a large randomised longitudinal asthma study of more than 1000 individuals found that treatment (with budesonide and nedocromil versus placebo) augmented the negative short-term effect of CO while having no effect on the other gaseous pollutants such as ozone and $\mathrm{NO}_{2}$ on airway responsiveness [187].

Statins and aspirin, while useful in primary prevention of coronary artery disease, require validation of their role in air pollution [16]. Statins reduced ambient particulate matter-induced lung inflammation by promoting the clearance of $\mathrm{PM}_{10}$ from lung tissues [188], but evidence in humans is limited. Therefore, while a general recommendation to optimise disease control through guideline-driven care is warranted, for each particular intervention in the face of air pollution, there needs be scrutiny of the evidence and further research to build that evidence base.

\section{Modify diet and supplement with antioxidants or anti-inflammatory agents (evidence grade D) Recommendation}

- Although a balanced diet is important for general wellbeing, we do not recommend taking any dietary supplement specifically to counteract the detrimental effects of air pollution on respiratory health, as none has been shown convincingly to have such benefits.

\section{Background and evidence}

Inhalation of air pollutants triggers direct and indirect induction of oxidative stress and inflammation [189], two key processes driving the pathogenesis of chronic respiratory diseases such as COPD and asthma that are exacerbated by air pollution [190].

A diet rich in antioxidants, fibre, protein and polyunsaturated fatty acids (PUFAs), such as the Mediterranean diet [191, 192], may reduce aberrant DNA methylation associated with cancer and cardiovascular disease following particulate matter exposure [193] and fish oil supplementation may protect against pro-allergic sensitisation effects of TRAP exposure [194]. Conversely, high-fat, low-PUFA "Western" diets may confer reduced protection against inflammatory insults such as air pollution [190-192].

Found in broccoli sprouts, sulforaphane is a potent ligand for the Nrf2 transcription factor, which regulates expression of antioxidant response element-related genes [190]. Consumption of a broccoli sprout beverage increased the excretion of carcinogenic air pollutants, including benzene, over a 12-week period, suggesting detoxication of some airborne pollutants [195]. Broccoli extracts also attenuated the nasal allergic response to diesel exhaust particles (DEPs) in atopic individuals with baseline airway DEP hypersensitivity [196]. Further large clinical trials are necessary to confirm the potential benefits of sulforaphane.

In healthy participants, pre-treatment with $N$-acetylcysteine diminished DEP-induced airway responsiveness in participants with baseline airway hyperresponsiveness [197]. In a second study of similar design, pre-treatment with vitamin $\mathrm{C}$ and $\mathrm{N}$-acetylcysteine augmented DEP-induced vasoconstriction [198]. Both studies observed a role for genetic variability in dictating responses to DEP exposure and antioxidant supplementation [197, 198].

Dietary supplementation with vitamins $\mathrm{C}$ and $\mathrm{E}$ reduced lung function decrements and bronchoconstriction induced by short-term exposure to ozone, $\mathrm{SO}_{2}$ and particulate matter [199], and reduced airway inflammation and improved lung function in ozone-exposed patients with asthma [190, 192, 199]; however, other randomised controlled trials failed to show positive effects [190, 192, 199]. In pregnant women exposed to $\mathrm{PM}_{2.5}$, insufficient vitamin $\mathrm{C}$ intake was associated with increased micronuclei frequency, a biomarker of genetic effects, associated with increased risk of cancer [200]. Overall, antioxidant treatments have not been properly subjected to a large phase 3 trial, or any phase 4 trial, in this context. It is unclear whether this is due to lack of financial incentive or indecision as to the ideal phenotype for such study, but larger well-resourced trials seem sensible given the scope of the problem and the desire for solutions in parallel with the community's driving focus on primary exposure reduction.

\section{Summary and conclusions}

Given the well-documented negative impacts of air pollution on respiratory health, strategies are needed to help providers, patients and the public minimise daily exposure [52]. Strategies will need to be tailored to the individual dependent on their levels of air pollution exposure, susceptibilities to air pollution exposure, 
TABLE 1 Recommended interventions, key supporting evidence and the overall strength of evidence based on the evidence grading used in the Global Initiative for Asthma guidelines 2019 [12]

\section{Recommendation}

Key evidence summary from January 1, 2013 to January 1, 2019

Strategies to minimise personal exposure to ambient air pollution

1. Use close-fitting particulate respirators such as N95 facemasks when ambient air pollution levels are high or when travelling to areas with high ambient levels of air pollution

2. Shift from motorised to active travel such as cycling or walking

3. Choose travel routes that minimise near-road air pollution exposure such as low-traffic routes and routes with open spaces, minimise travel during peak times, and avoid delays in areas of high air pollution where possible

4. Optimise driving style and vehicle settings, e.g. drive with windows closed when in traffic, maintain car air filtration systems and avoid engine idling

5. Exercise regularly but moderate outdoor activity when and where air pollution levels are high

6. Be aware of local air pollution levels

\section{Strategies to minimise personal exposure to household air pollution}

7. Use clean fuels, ensure adequate household ventilation where possible and adopt improved cookstoves where resources remain sufficient
Four small-scale studies in healthy adults, mostly randomised and noncontrolled in design, suggest use of close-fitting N95 particulate respirators may reduce the impact of ambient air pollution on respiratory and cardiovascular health outcomes.

Several systematic reviews, health impact assessments and epidemiological studies suggest that the benefits of physical activity when actively commuting versus using motorised transport outweighed the risks associated with an increased inhaled dose of air pollution. In highly polluted cities $\left(\mathrm{PM}_{2.5} 160 \mu \mathrm{g} \cdot \mathrm{m}^{-3}\right)$ up to $30 \mathrm{~min}$ of cycling and $6.25 \mathrm{~h}$ of walking per day would lead to a net reduction in all-cause mortality versus staying at home. Also, shift to active travel could improve air quality by reducing emissions.

While there is evidence that using low-traffic versus high-traffic routes can minimise air pollution exposure when cycling or walking, few studies have demonstrated respiratory health benefits, particularly for susceptible individuals. Only one randomised controlled study found that older subjects and adults with COPD should select walking routes with low levels of traffic versus high levels to avoid negating the cardiorespiratory benefits of exercise.

To minimise individual exposure to traffic-related air pollution, evidence from comparative studies supports driving with windows closed when in traffic, maintaining car air filtration systems, keeping the air on internal circulation and avoiding engine idling. However, no studies were identified that examined the effect of driving style, vehicle or engine settings on pulmonary function. Despite a lack of clinical studies on health outcomes, the potential benefit of reducing air pollution levels means that this is an action to consider.

Current evidence from epidemiological and comparative studies suggests that engaging in physical activity in an air-polluted environment may not completely negate the positive effects of exercise. Individuals should be advised to exercise away from traffic whenever possible and plan outdoor activities around local forecasts.

Individuals should be encouraged to check their local air quality forecast and maps, and use this information to make informed decisions to reduce their exposure such as seeking alternative low air pollution routes or moderating outdoor activities. No studies were identified that examined an association between Air Quality Index awareness and respiratory health outcomes; however, the potential benefit of knowing when air pollution levels are high and implementing strategies to minimise exposure means that this is an action to consider.

Some small-scale, noncrossover intervention studies suggest that transitioning away from cooking with solid fuels to electric or clean-burning gas (liquid petroleum gas) stoves can improve respiratory health outcomes in adults and children. The Global Initiative for Chronic Obstructive Lung Disease guidelines recommend use of nonpolluting cooking stoves and efficient ventilation to minimise exposure to indoor air pollution as a risk factor for developing COPD [149]. 
TABLE 1 Continued

Recommendation

Key evidence summary from January 1, 2013 to January 1, 2019

Overall strength of evidence

8. Use portable air cleaners combined with measures to reduce the source of household air pollution and strategies to improve ventilation

\section{Effect modifiers}

9. Treat and manage respiratory conditions

10. Modify diet and supplement with antioxidants or anti-inflammatory agents
There is evidence from mostly randomised, crossover intervention studies

C to support the use of portable air cleaners to reduce respiratory health effects among the general population who face regular exposure to household air pollution although evidence for benefit in older individuals is lacking. Portable air cleaners fitted with HEPA filters are most effective for filtering particles in the home.

Effective management of COPD and asthma in patients is vital for D mitigating the increased risk from ambient or indoor air pollution exposure. The implementation of established primary, secondary and tertiary interventions for cardiopulmonary diseases le.g. controlling hypertension, lowering lipids, reducing obesity, promoting physical activity, smoking cessation and avoidance of second-hand smokel will serve to reduce the overall burden of disease associated with air pollution exposure.

A healthy, balanced diet is favoured as a key determinant to health throughout life and associated with reductions in the risk of chronic lung diseases known to be compounded by air pollution.

$\mathrm{PM}_{2.5}$ : particles with a $50 \%$ cut-off aerodynamic diameter $<2.5 \mu \mathrm{m}$; COPD: chronic obstructive pulmonary disease; HEPA: high-efficiency particulate air.

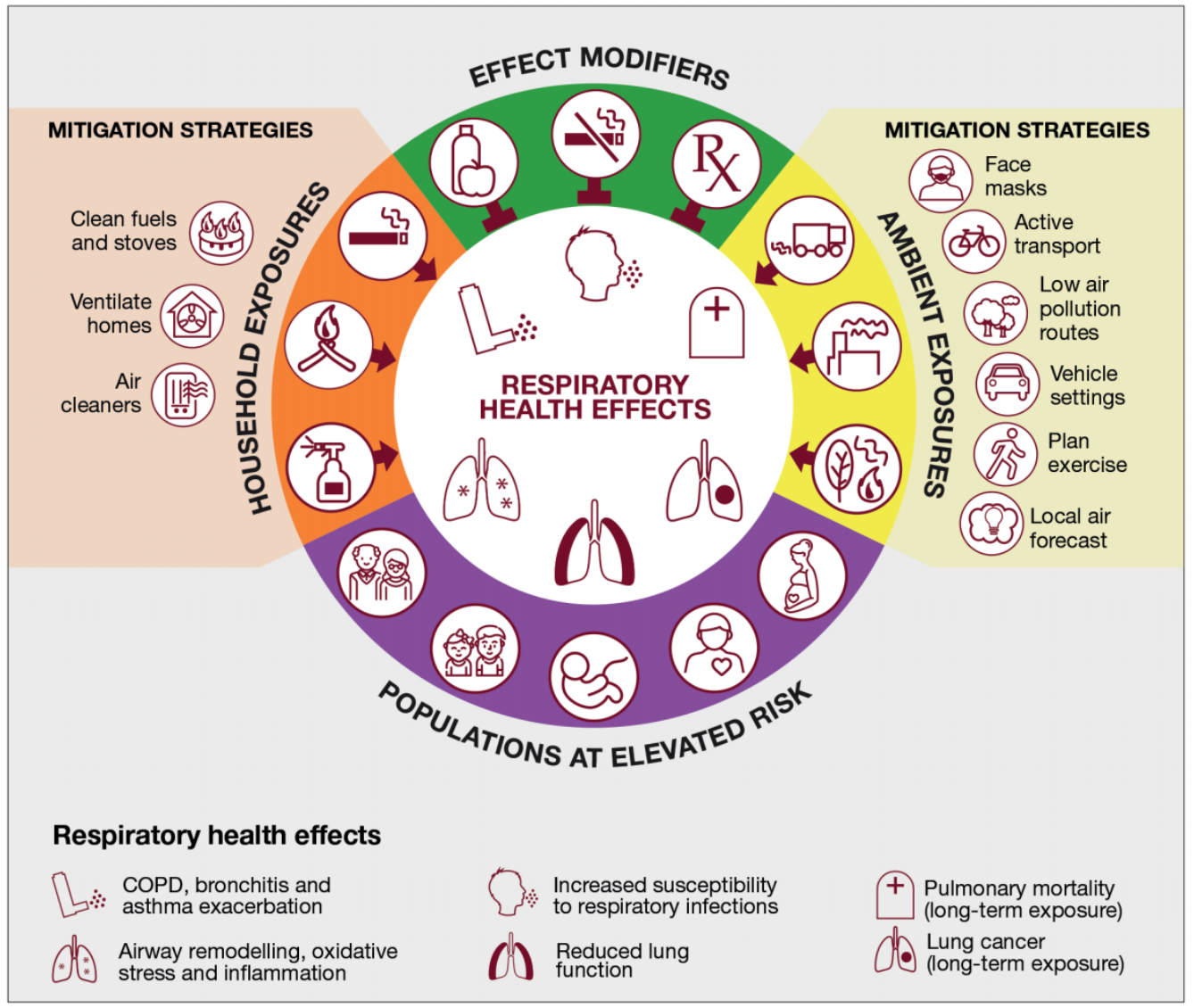

FIGURE 3 Key elements in mitigating air pollution exposure and protecting respiratory health. 


\section{TABLE 2 Gaps in the evidence and areas for further research}

1. Use facemasks under appropriate circumstances

2. Shift from motorised to active transport whenever possible

3. Choose travel routes that minimise near-road air pollution exposure

4. Optimise driving style and vehicle settings

5. Moderate outdoor physical activity when and where air pollution levels are high

\section{Monitor air pollution levels}

Knowledge about the role of facemasks in reducing exposures to air pollution is rudimentary. There is a need for more extensive, rigorous and standardised testing of commercially available air pollution masks.

Studies assessing the impact of facemasks on health outcomes should include measurement of exposure reduction (by monitoring particulate concentrations inside the facepiece) to more accurately assess exposure-response relationships [19]. It would be of value to determine whether the proportion of particles removed by the mask is sufficient to provide health benefits and how long people must wear a mask for those benefits to manifest.

Studies are needed to assess whether wearing masks that filter gaseous pollutants (in addition to fine particles) provides added respiratory benefits.

There are very limited data on long-term respiratory health effects of increased air pollution exposure among passive and active commuters, warranting additional research in this area.

Data on commuters' perceptions about air pollution exposure and how these perceptions may influence their commute in terms of route, time of day and mode of transportation are scarce. Understanding these perceptions may help guide future educational efforts aimed at reducing active commuters' air pollution exposures [37].

Children and their families should be provided with information on how to minimise exposure to TRAP by prioritising low air pollution routes, integrated with cycling and walking plans when commuting to school [74].

Mobile phone applications, news feeds and websites can help individuals plan their activities or travel routes to minimise air pollution exposures [99, 204-206]. Evidence is needed to demonstrate that these interventions reduce air pollution exposure and lead to associated health benefits.

Much of the research focus has been on developed countries. Strategies to minimise TRAP in countries such as China and India where there has been a sharp increase in the number of motor vehicles needs further exploration; in these countries the options to avoid highly polluted routes are often limited or nonexistent.

There is evidence to show that changes to driving style and vehicle settings can lower levels of local air pollution; however, studies are needed to determine the potential health benefits associated with reduced exposure to TRAP related to changes in driving behaviours.

There is a need to identify approaches that encourage more efficient, less polluting driving behaviour.

While electric cars are the vehicles of the future for their low emissions, they still generate pollutants, e.g. from tyres and other parts of engine, and the impact on respiratory health needs to be studied.

The level of air pollution or physical activity at which exercise becomes more harmful than beneficial is not fully understood, limiting the ability to effectively balance the benefits and risks.

Studies are needed to assess whether associations between long- and short-term concentrations of air pollution and indicators of health risks can be modified by levels and types of physical activity, as well as the locations where physical activity is performed.

Gene-environment interaction is an emerging focus of research and the role of genetics in the health effects of combined physical activity and air pollution exposure warrants further investigation.

Current data on efficacy of Air Quality Index alerts and wearable technology in increasing air pollution-protective behaviour is conflicting and often relies on self-report [112]. Further research is needed to establish how individuals can be best motivated and assisted to act on advice to reduce air pollution exposure.

Standardisation of personal exposure monitors is needed to ensure accurate detection of major air pollutants, and their precision, accuracy and generalisability in capturing long-term or usual exposures requires further evaluation.

Wearable sensors and location-based monitoring fail to account for the impact of ventilation rate on inhalation of pollutants; newer personal monitoring devices that incorporate these measurements are necessary to provide more accurate measures of air pollution exposure.

The full benefits of knowing one's personal air pollution exposure still needs to be explored and one possibility is that it may be a powerful determinant of changing behaviour towards reduced exposure. 


\section{TABLE 2 Continued}

7. Use clean fuels, ensure adequate household ventilation where possible and adopt improved cookstoves where resources remain sufficient

\section{Use portable air cleaners as an indoor} environmental intervention

9. Treat and manage respiratory conditions

10. Modify diet and supplement with antioxidants or anti-inflammatory agents
Education on the respiratory health risks associated with burning solid fuels for cooking and heating is lacking.

Large-scale RCTs are needed to examine the effect of improved household ventilation on respiratory health outcomes.

Large-scale RCTs are needed to examine the effect of transitioning away from cooking with solid fuels on respiratory health outcomes. Until the findings are known, it is difficult to recommend household energy interventions that will reliably improve respiratory health.

The body of evidence supporting the role of portable air cleaners in reducing exposures to indoor air pollutants and providing benefit is growing; however, there is need for more extensive, rigorous and standardised testing of commercially available portable air cleaners, and their potential to reduce exposure to household air pollution and provide respiratory health benefits.

More studies are needed to assess whether portable air cleaners that filter gaseous pollutants (in addition to particulate matter) provide added respiratory benefits.

Education on the harmful effects of household air pollution including second-hand smoke derived from indoor cigarette smoking, in particular the association with asthma and the development of chronic lung disease in later life, is needed to foster behavioural change and improve respiratory health.

Preliminary evidence in animal studies that pharmacological interventions such as statins may help protect lung inflammation triggered by air pollution exposures need to be confirmed [188].

Studies are needed to identify genetic polymorphisms that modify airway responses to air pollution, clarify the role of epigenetic changes and investigate the effectiveness of new preventive or therapeutic approaches, including for people with low levels of antioxidants.

Large, well-designed RCTs are necessary to confirm the beneficial effects of high fruit and vegetable intake, and of the Mediterranean diet, on respiratory health outcomes and effects of air pollution exposure.

Clearer mechanistic understanding and assessment of combinations of supplements and air pollution exposures are warranted to establish whether there are optimal supplement regimens for particular populations, diseases, genotypes or patterns of pollutant exposure.

Sulforaphane supplementation may present a promising mechanism to reduce the impact of air pollution $[195,196]$ and further large RCTs are needed.

TRAP: traffic-related air pollution; RCT: randomised controlled trial.

health literacy, financial resources and support networks. Advisors need to develop an approach that allows flexibility based on the perception of a given individual, given the known variability in how each person perceives and responds to the threat of air pollution [201]. Regardless, these strategies can be impactful, because there is no "safe" lower limit of air pollution and because of the steep exposureresponse curve at lower levels of air pollution [2]. The benefits may be even more pronounced for susceptible individuals such as those with chronic pulmonary conditions, at extremes of age [51, 74, 106], pregnant women and in utero [202].

The recommendations are summarised in table 1 and figure 3, and the key supporting evidence for each recommendation (from studies that included at least one respiratory health outcome) are described in supplementary table S3.

These evidence-based, practical recommendations should serve as a useful reference for advising patients and the public on individual-level interventions to reduce exposure to air pollution and mitigate the associated respiratory health risks. While we, like others [203], reveal that the quality of the evidence is lacking overall, we have supplemented what the suboptimal evidence suggests with expert perspective, so as to provide guidance to those who want it; it is important to give such advice to the global population that eagerly seeks a rational approach to personal decisions now. In parallel, gaps in the evidence and areas for further research are described in table 2, motivating efforts to provide a more robust evidence base for validated advice to all of us who face the daily threat of air pollution.

Acknowledgements: Editorial writing assistance, supported financially by GSK, was provided by Gill McFeat (Ogilvy 4D Oxford, UK).

Author contributions: The authors were fully responsible for all content and editorial decisions, were involved at all stages of manuscript development and have approved the final version. 
Conflict of interest: C. Carlsten reports that he has been an advisor for the Clean Breathing Institute of GSK Consumer Health Care, during the writing of the report. S. Salvi reports that he has been an advisor for the Clean Breathing Institute of GSK Consumer Health Care, during the writing of the report. G.W.K. Wong reports that he has been an advisor for the Clean Breathing Institute of GSK Consumer Health Care, during the writing of the report. K.F. Chung reports that he has been an advisor for the Clean Breathing Institute of GSK Consumer Health Care, during the writing of the report; and has received honoraria for participating in advisory board meetings of GSK, AstraZeneca, Novartis, Merck, Boehringer Ingelheim and Teva regarding treatments for asthma and COPD and has also been remunerated for speaking engagements.

Support statement: This work was supported by GSK. GSK had no role in the collection, analysis and interpretation of data; in the writing of the report; and in the decision to submit the paper for publication. Funding information for this article has been deposited with the Crossref Funder Registry.

\section{References}

1 World Health Organization. Ten threats to global health in 2019. 2018. www.who.int/emergencies/ten-threats-toglobal-health-in-2019 Date last accessed: February 8, 2019.

2 Burnett R, Chen H, Szyszkowicz M, et al. Global estimates of mortality associated with long-term exposure to outdoor fine particulate matter. Proc Natl Acad Sci USA 2018; 115: 9592-9597.

3 Landrigan PJ, Fuller R, Acosta NJR, et al. The Lancet Commission on pollution and health. Lancet 2018; 391: 462-512.

4 Assad NA, Kapoor V, Sood A. Biomass smoke exposure and chronic lung disease. Curr Opin Pulm Med 2016; 22: $150-157$.

5 Traboulsi $\mathrm{H}$, Guerrina N, Iu M, et al. Inhaled pollutants: the molecular scene behind respiratory and systemic diseases associated with ultrafine particulate matter. Int J Mol Sci 2017; 18: 243.

6 Hedley AJ, Wong CM, Thach TQ, et al. Cardiorespiratory and all-cause mortality after restrictions on sulphur content of fuel in Hong Kong: an intervention study. Lancet 2002; 360: 1646-1652.

7 Clancy L, Goodman P, Sinclair H, et al. Effect of air-pollution control on death rates in Dublin, Ireland: an intervention study. Lancet 2002; 360: 1210-1214.

8 Shi J, Lin Z, Chen R, et al. Cardiovascular benefits of wearing particulate-filtering respirators: a randomized crossover trial. Environ Health Perspect 2017; 125: 175-180.

9 Pope CA, Cropper M, Coggins J, et al. Health benefits of air pollution abatement policy: role of the shape of the concentration-response function. J Air Waste Manag Assoc 2015; 65: 516-522.

10 Powell P, Brunekreef B, Grigg J. How do you explain the risk of air pollution to your patients? Breathe 2016; 12: 201-203.

11 Royal College of Physicians. Every Breath We Take: The Lifelong Impact of Air Pollution. London, RCP, 2016.

12 Global Initiative for Asthma. Global strategy for asthma management and prevention. 2019. https://ginasthma.org/ wp-content/uploads/2019/06/GINA-2019-main-report-June-2019-wms.pdf Date last accessed: October 9, 2019.

13 Centers for Disease Control and Prevention. Non-occupational uses of respiratory protection - what public health organizations and users need to know. 2018. https://blogs.cdc.gov/niosh-science-blog/2018/01/04/ respirators-public-use Date last accessed: February 6, 2019.

14 US Food and Drug Administration. Masks and N95 respirators. 2018. www.fda.gov/medicaldevices/ productsandmedicalprocedures/generalhospitaldevicesandsupplies/personalprotectiveequipment/ucm055977.htm Date last accessed: February 6, 2019.

15 Rajper SA, Ullah S, Li Z. Exposure to air pollution and self-reported effects on Chinese students: a case study of 13 megacities. PLoS One 2018; 13: e0194364.

16 Laumbach R, Meng Q, Kipen $\mathrm{H}$. What can individuals do to reduce personal health risks from air pollution? J Thorac Dis 2015; 7: 96-107.

17 Jiang XQ, Mei XD, Feng D. Air pollution and chronic airway diseases: what should people know and do? $J$ Thorac Dis 2016; 8: E31-E40.

18 Pacitto A, Amato F, Salmatonidis A, et al. Effectiveness of commercial face masks to reduce personal PM exposure. Sci Total Environ 2019; 650: 1582-1590.

19 Cherrie JW, Apsley A, Cowie H, et al. Effectiveness of face masks used to protect Beijing residents against particulate air pollution. Occup Environ Med 2018; 75: 446-452.

20 Yu Y, Jiang L, Zhuang Z, et al. Fitting characteristics of N95 filtering-facepiece respirators used widely in China. PLoS One 2014; 9: e85299.

21 Johnson AT. Respirator masks protect health but impact performance: a review. J Biol Eng 2016; 10: 4.

22 MacIntyre CR, Seale H, Dung TC, et al. A cluster randomised trial of cloth masks compared with medical masks in healthcare workers. BMJ Open 2015; 5: e006577.

23 Guan W-J, Zheng X-Y, Chung KF, et al. Impact of air pollution on the burden of chronic respiratory diseases in China: time for urgent action. Lancet 2016; 388: 1939-1951.

24 Guan T, Hu S, Han Y, et al. The effects of facemasks on airway inflammation and endothelial dysfunction in healthy young adults: a double-blind, randomized, controlled crossover study. Part Fibre Toxicol 2018; 15: 30.

25 Shakya KM, Noyes A, Kallin R, et al. Evaluating the efficacy of cloth facemasks in reducing particulate matter exposure. J Expo Sci Environ Epidemiol 2017; 27: 352-357.

26 Patel D, Shibata T, Wilson J, et al. Challenges in evaluating PM concentration levels, commuting exposure, and mask efficacy in reducing PM exposure in growing, urban communities in a developing country. Sci Total Environ 2016; 543: 416-424.

27 Shakya KM, Rupakheti M, Aryal K, et al. Respiratory effects of high levels of particulate exposure in a cohort of traffic police in Kathmandu, Nepal. J Occup Environ Med 2016; 58: e218-e225.

28 Yang X, Jia X, Dong W, et al. Cardiovascular benefits of reducing personal exposure to traffic-related noise and particulate air pollution: a randomized crossover study in the Beijing subway system. Indoor Air 2018; 28: 777-786.

29 Laumbach RJ, Kipen HM, Ko S, et al. A controlled trial of acute effects of human exposure to traffic particles on pulmonary oxidative stress and heart rate variability. Part Fibre Toxicol 2014; 11: 45. 
Wang A, Fan R, Zhou X, et al. Hot-pressing method to prepare imidazole-based Zn(II) metal-organic complexes coatings for highly efficient air filtration. ACS Appl Mater Interfaces 2018; 10: 9744-9755.

31 Wang N, Cai M, Yang X, et al. Electret nanofibrous membrane with enhanced filtration performance and wearing comfortability for face mask. J Colloid Interface Sci 2018; 530: 695-703.

32 Zhao Y, Low Z-X, Feng S, et al. Multifunctional hybrid porous filters with hierarchical structures for simultaneous removal of indoor VOCs, dusts and microorganisms. Nanoscale 2017; 9: 5433-5444.

33 Open Biomedical Initiative. Breathe easier with Sendinaden's 3D printed Pattern Breathe mask. 2015. www. openbiomedical.org/breathe-easier-with-sendinadens-3d-printed-pattern-breathe-mask Date last accessed: February 6, 2019.

34 Dons E, Int Panis L, Van Poppel M, et al. Personal exposure to black carbon in transport microenvironments. Atmos Environ 2012; 55: 392-398.

35 de Nazelle A, Bode O, Orjuela JP. Comparison of air pollution exposures in active vs. passive travel modes in European cities: a quantitative review. Environ Int 2017; 99: 151-160.

36 Karanasiou A, Viana M, Querol X, et al. Assessment of personal exposure to particulate air pollution during commuting in European cities - recommendations and policy implications. Sci Total Environ 2014; 490: $785-797$.

37 Chaney RA, Sloan CD, Cooper VC, et al. Personal exposure to fine particulate air pollution while commuting: an examination of six transport modes on an urban arterial roadway. PLoS One 2017; 12: e0188053.

38 Okokon EO, Yli-Tuomi T, Turunen AW, et al. Particulates and noise exposure during bicycle, bus and car commuting: a study in three European cities. Environ Res 2017; 154: 181-189.

39 Ozgen S, Ripamonti G, Malandrini A, et al. Particle number and mass exposure concentrations by commuter transport modes in Milan, Italy. AIMS Environ Sci 2016; 3: 168-184.

40 Carvalho AM, Krecl P, Targino AC. Variations in individuals' exposure to black carbon particles during their daily activities: a screening study in Brazil. Environ Sci Pollut Res Int 2018; 25: 18412-18423.

41 Hankey S, Lindsey G, Marshall JD. Population-level exposure to particulate air pollution during active travel: planning for low-exposure, health-promoting cities. Environ Health Perspect 2017; 125: 527-534.

42 Good N, Mölter A, Ackerson C, et al. The Fort Collins Commuter Study: impact of route type and transport mode on personal exposure to multiple air pollutants. J Expo Sci Environ Epidemiol 2016; 26: 397-404.

43 Cepeda M, Schoufour J, Freak-Poli R, et al. Levels of ambient air pollution according to mode of transport: a systematic review. Lancet Public Health 2017; 2: e23-e34.

44 Kumar P, Rivas I, Singh AP, et al. Dynamics of coarse and fine particle exposure in transport microenvironments. NPJ Clim Atmos Sci 2018; 1: 11.

45 Woodcock J, Tainio M, Cheshire J, et al. Health effects of the London bicycle sharing system: health impact modelling study. BMJ 2014; 348: g425.

46 Doorley R, Pakrashi V, Ghosh B. Quantifying the health impacts of active travel: assessment of methodologies. Transp Rev 2015; 35: 559-582.

47 Mueller N, Rojas-Rueda D, Cole-Hunter T, et al. Health impact assessment of active transportation: a systematic review. Prev Med 2015; 76: 103-114.

48 Xia T, Nitschke M, Zhang Y, et al. Traffic-related air pollution and health co-benefits of alternative transport in Adelaide, South Australia. Environ Int 2015; 74: 281-290.

49 Andersen ZJ, de Nazelle A, Mendez MA, et al. A study of the combined effects of physical activity and air pollution on mortality in elderly urban residents: the Danish diet, cancer, and health cohort. Environ Health Perspect 2015; 123: 557-563.

50 Tainio M, de Nazelle AJ, Götschi T, et al. Can air pollution negate the health benefits of cycling and walking? Prev Med 2016; 87: 233-236.

51 Sinharay R, Gong J, Barratt B, et al. Respiratory and cardiovascular responses to walking down a traffic-polluted road compared with walking in a traffic-free area in participants aged 60 years and older with chronic lung or heart disease and age-matched healthy controls: a randomised, crossover study. Lancet 2018; 391: 339-349.

52 National Institute for Health and Care Excellence. Air pollution: outdoor air quality and health. 2018. www.nice. org.uk/guidance/qs181/documents/briefing-paper Date last accessed: February 4, 2019.

53 US Environmental Protection Agency. AirNow. You can help keep the air cleaner - every day! 2018. https:/ airnow.gov/index.cfm?action=resources.whatyoucando\#trans Date last accessed: February 5, 2019.

54 Raza W, Forsberg B, Johansson C, et al. Air pollution as a risk factor in health impact assessments of a travel mode shift towards cycling. Glob Health Action 2018; 11: 1429081.

55 Gaffney AW, Hang J-Q, Lee M-S, et al. Commuting mode and pulmonary function in Shanghai, China. Eur Respir J 2016; 47: 733-741.

56 Jereb B, Batkovič T, Herman L, et al. Exposure to black carbon during bicycle commuting - alternative route selection. Atmosphere 2018; 9: 21.

57 Davies G, Whyatt JD. A network-based approach for estimating pedestrian journey-time exposure to air pollution. Sci Total Environ 2014; 485-486: 62-70.

58 Dirks K, Wang J, Khan A, et al. Air pollution exposure in relation to the commute to school: a Bradford UK case study. Int J Environ Res Public Health 2016; 13: 1064

59 Goel A, Kumar P. A review of fundamental drivers governing the emissions, dispersion and exposure to vehicle-emitted nanoparticles at signalised traffic intersections. Atmos Environ 2014; 97: 316-331.

60 Goel A, Kumar P. Characterisation of nanoparticle emissions and exposure at traffic intersections through fastresponse mobile and sequential measurements. Atmos Environ 2015; 107: 374-390.

61 Choi W, Ranasinghe D, Bunavage $\mathrm{K}$, et al. The effects of the built environment, traffic patterns, and micrometeorology on street level ultrafine particle concentrations at a block scale: results from multiple urban sites. Sci Total Environ 2016; 553: 474-485.

62 Jarjour S, Jerrett M, Westerdahl D, et al. Cyclist route choice, traffic-related air pollution, and lung function: a scripted exposure study. Environ Health 2013; 12: 14.

63 Goel A, Kumar P. Zone of influence for particle number concentrations at signalised traffic intersections. Atmos Environ 2015; 123: 25-38.

64 Ramos CA, Silva JR, Faria T, et al. Exposure assessment of a cyclist to particles and chemical elements. Environ Sci Pollut Res Int 2017; 24: 11879-11889. 
Park H-Y, Gilbreath S, Barakatt E. Respiratory outcomes of ultrafine particulate matter (UFPM) as a surrogate measure of near-roadway exposures among bicyclists. Environ Health 2017; 16: 6. personal air pollution exposures among cyclists in Montreal, Canada. J Expo Sci Environ Epidemiol 2013; 23: 46-51. MacNaughton P, Melly S, Vallarino J, et al. Impact of bicycle route type on exposure to traffic-related air pollution. Sci Total Environ 2014; 490: 37-43.

68 Ham W, Vijayan A, Schulte $\mathrm{N}$, et al. Commuter exposure to $\mathrm{PM}_{2.5}, \mathrm{BC}$, and UFP in six common transport microenvironments in Sacramento, California. Atmos Environ 2017; 167: 335-345.

69 Pattinson W, Kingham S, Longley I, et al. Potential pollution exposure reductions from small-distance bicycle lane separations. J Transp Health 2017; 4: 40-52.

70 Hooper LG, Kaufman JD. Ambient air pollution and clinical implications for susceptible populations. Ann Am Thorac Soc 2018; 15: S64-S68.

71 Soyiri IN, Alcock I. Green spaces could reduce asthma admissions. Lancet Respir Med 2018; 6: e1.

72 Braubach M, Egorov A, Mudu P, et al. Effects of urban green space on environmental health, equity and resilience. In: Kabisch N, Korn H, Stadler J, et al. eds. Nature-Based Solutions to Climate Change Adaptation in Urban Areas. Cham, Springer, 2017; pp. 187-205.

73 Parmes E, Pesce G, Sabel CE, et al. Influence of residential land cover on childhood allergic and respiratory symptoms and diseases: evidence from 9 European cohorts. Environ Res 2019; 183: 108953.

74 UNICEF. The toxic school run. 2018. www.unicef.org.uk/wp-content/uploads/2018/09/UUK-research-briefingThe-toxic-school-run-September-2018.pdf Date last accessed: February 6, 2019.

75 Kean AJ, Harley RA, Kendall GR. Effects of vehicle speed and engine load on motor vehicle emissions. Environ Sci Technol 2003; 37: 3739-3746.

76 Leavey A, Reed N, Patel S, et al. Comparing on-road real-time simultaneous in-cabin and outdoor particulate and gaseous concentrations for a range of ventilation scenarios. Atmos Environ 2017; 166: 130-141.

77 Quiros DC, Lee ES, Wang R, et al. Ultrafine particle exposures while walking, cycling, and driving along an urban residential roadway. Atmos Environ 2013; 73: 185-194.

78 Williams RD, Knibbs LD. Daily personal exposure to black carbon: a pilot study. Atmos Environ 2016; 132: 296-299.

79 Li B, Lei X-N, Xiu G-L, et al. Personal exposure to black carbon during commuting in peak and off-peak hours in Shanghai. Sci Total Environ 2015; 524-525: 237-245.

80 Kolluru SSR, Patra AK, Sahu SP. A comparison of personal exposure to air pollutants in different travel modes on national highways in India. Sci Total Environ 2018; 619-620: 155-164.

81 Ding H, Zhang Y, Sun H, et al. Analysis of the PM2.5 distribution and the transfer characteristic in a car-cabin. Procedia Eng 2015; 121: 875-880.

$82 \mathrm{Xu} \mathrm{B}$, Zhu Y. Investigation on lowering commuters' in-cabin exposure to ultrafine particles. Transp Res D Transp Environ 2013; 18: 122-130.

83 Lee Y-Y, Lin S-L, Yuan C-S, et al. Reduction of atmospheric fine particle level by restricting the idling vehicles around a sensitive area. J Air Waste Manag Assoc 2018; 68: 656-670.

84 Quintana PJE, Khalighi M, Castillo Quiñones JE, et al. Traffic pollutants measured inside vehicles waiting in line at a major US-Mexico Port of Entry. Sci Total Environ 2018; 622-623: 236-243.

85 Kim K-H, Szulejko JE, Jo H-J, et al. Measurements of major VOCs released into the closed cabin environment of different automobiles under various engine and ventilation scenarios. Environ Pollut 2016; 215: 340-346.

86 Ryan PH, Reponen T, Simmons M, et al. The impact of an anti-idling campaign on outdoor air quality at four urban schools. Environ Sci Process Impacts 2013; 15: 2030-2037.

87 Borken-Kleefeld J, Chen Y. New emission deterioration rates for gasoline cars - results from long-term measurements. Atmos Environ 2015; 101: 58-64.

88 International Agency for Research on Cancer Scientific Publications. Air pollution and cancer. 2013. www.iarc.fr/ wp-content/uploads/2018/07/AirPollutionandCancer161.pdf Date last accessed: February 6, 2019.

89 Giles LV, Koehle MS. The health effects of exercising in air pollution. Sports Med 2014; 44: $223-249$.

90 Si Q, Cardinal BJ. The health impact of air pollution and outdoor physical activity on children and adolescents in Mainland China. J Pediatr 2017; 180: 251-255.

91 Kubesch NJ, de Nazelle A, Westerdahl D, et al. Respiratory and inflammatory responses to short-term exposure to traffic-related air pollution with and without moderate physical activity. Occup Environ Med 2015; 72: $284-293$.

92 Laeremans M, Dons E, Avila-Palencia I, et al. Short-term effects of physical activity, air pollution and their interaction on the cardiovascular and respiratory system. Environ Int 2018; 117: 82-90.

93 Matt F, Cole-Hunter T, Donaire-Gonzalez D, et al. Acute respiratory response to traffic-related air pollution during physical activity performance. Environ Int 2016; 97: 45-55.

94 Laeremans M, Dons E, Avila-Palencia I, et al. Black carbon reduces the beneficial effect of physical activity on lung function. Med Sci Sports Exerc 2018; 50: 1875-1881.

95 Lamichhane DK, Leem JH, Kim HC. Associations between ambient particulate matter and nitrogen dioxide and chronic obstructive pulmonary diseases in adults and effect modification by demographic and lifestyle factors. Int J Environ Res Public Health 2018; 15: 363

96 Zhang Z, Hoek G, Chang L-Y, et al. Particulate matter air pollution, physical activity and systemic inflammation in Taiwanese adults. Int J Hyg Environ Health 2018; 221: 41-47.

97 Fisher JE, Loft S, Ulrik CS, et al. Physical activity, air pollution, and the risk of asthma and chronic obstructive pulmonary disease. Am J Respir Crit Care Med 2016; 194: 855-865.

98 Cai DP, He YM. Daily lifestyles in the fog and haze weather. J Thorac Dis 2016; 8: E75-E77.

99 World Air Quality Index. World's air pollution: real-time air quality index. 2019. https://waqi.info Date last accessed: February 4, 2019.

100 US Environmental Protection Agency. Air Quality Index. A guide to air quality and your health. 2014. www3. epa.gov/airnow/aqi_brochure_02_14.pdf Date last accessed: February 5, 2019.

101 An R, Xiang X. Ambient fine particulate matter air pollution and leisure-time physical inactivity among US adults. Public Health 2015; 129: 1637-1644.

102 Roberts JD, Voss JD, Knight B. The association of ambient air pollution and physical inactivity in the United States. PLoS One 2014; 9: e90143. 
103 An R, Zhang S, Ji M, et al. Impact of ambient air pollution on physical activity among adults: a systematic review and meta-analysis. Perspect Public Health 2018; 138: 111-121.

$104 \mathrm{Hu} \mathrm{L}$, Zhu L, Xu Y, et al. Relationship between air quality and outdoor exercise behavior in China: a novel mobile-based study. Int J Behav Med 2017; 24: 520-527.

105 Ma Y, Yuan B, Fan S, et al. Association between air quality and sedentary time in 3270 Chinese adults: application of a novel technology for posture determination. J Clin Med 2018; 7: 257.

106 Araban M, Tavafian SS, Zarandi SM, et al. A behavioral strategy to minimize air pollution exposure in pregnant women: a randomized controlled trial. Environ Health Prev Med 2017; $22: 1$.

107 Jasemzadeh M, Khafaie MA, Jaafarzadeh N, et al. Effectiveness of a theory-based mobile phone text message intervention for improving protective behaviors of pregnant women against air pollution: a randomized controlled trial. Environ Sci Pollut Res Int 2018; 25: 6648-6655.

108 Lemes S. Air Quality Index (AQI) - comparative study and assessment of an appropriate model for B\&H. Presented at 12th Scientific/Research Symposium with International Participation Metallic and Nonmetallic Materials, Vlašić. 2018. www.researchgate.net/publication/324602557_Air_Quality_Index_AQI_-_Comparative_ Study_And_Assessment_Of_An_Appropriate_Model_For_BH Date last accessed: March 27, 2020.

109 Hu J, Ying Q, Wang Y, et al. Characterizing multi-pollutant air pollution in China: comparison of three air quality indices. Environ Int 2015; 84: 17-25.

110 Kumari S, Jain MK. A critical review on air quality index. In: Singh VP, Yadav S, Yadava RN, eds. Environmental Pollution. Singapore, Springer, 2018; pp. 87-102.

111 Perlmutt L, Stieb D, Cromar K. Accuracy of quantification of risk using a single-pollutant Air Quality Index. J Expo Sci Environ Epidemiol 2017; 27: 24-32.

112 Ramos F, Trilles S, Muñoz A, et al. Promoting pollution-free routes in smart cities using air quality sensor networks. Sensors 2018; 18: 2507.

113 Li X, Xiao J, Lin H, et al. The construction and validity analysis of AQHI based on mortality risk: a case study in Guangzhou, China. Environ Pollut 2017; 220: 487-494.

114 US Environmental Protection Agency. Air Quality Index - a guide to air quality and your health. 2017. www. airnow.gov/index.cfm?action=aqi_brochure.index Date last accessed: February 5, 2019.

115 Hadley MB, Baumgartner J, Vedanthan R. Developing a clinical approach to air pollution and cardiovascular health. Circulation 2018; 137: 725-742.

116 Barts Health NHS Trust. Action on air pollution: collaboration and public health at scale. 2014. www. nhssustainabilityday.co.uk/wp-content/uploads/2014/09/Action-on-Air-Pollution Barts-Health-NHS-Trust-June-2016.pdf Date last accessed: October 22, 2018.

117 D'Antoni D, Smith L, Auyeung V, et al. Psychosocial and demographic predictors of adherence and non-adherence to health advice accompanying air quality warning systems: a systematic review. Environ Health 2017; 16: 100

118 Borbet TC, Gladson LA, Cromar KR. Assessing air quality index awareness and use in Mexico City. BMC Public Health 2018; 18: 538.

119 Hojaiji H, Kalantarian H, Bui AAT, et al. Temperature and humidity calibration of a low-cost wireless dust sensor for real-time monitoring. 2017. https://ieeexplore.ieee.org/document/7894056 Date last accessed: March 27, 2020

120 Koehler KA, Peters TM. New methods for personal exposure monitoring for airborne particles. Curr Environ Health Rep 2015; 2: 399-411.

121 Steinle S, Reis S, Sabel CE. Quantifying human exposure to air pollution - moving from static monitoring to spatio-temporally resolved personal exposure assessment. Sci Total Environ 2013; 443: 184-193.

122 Dons E, Laeremans M, Orjuela JP, et al. Wearable sensors for personal monitoring and estimation of inhaled traffic-related air pollution: evaluation of methods. Environ Sci Technol 2017; 51: 1859-1867.

123 Su JG, Jerrett M, Meng Y-Y, et al. Integrating smart-phone based momentary location tracking with fixed site air quality monitoring for personal exposure assessment. Sci Total Environ 2015; 506-507: 518-526.

124 Larkin A, Williams DE, Kile ML, et al. Developing a smartphone software package for predicting atmospheric pollutant concentrations at mobile locations. Comput J 2015; 58: 1431-1442.

125 Wong-Parodi G, Dias MB, Taylor M. Effect of using an indoor air quality sensor on perceptions of and behaviors toward air pollution (Pittsburgh Empowerment Library Study): online survey and interviews. JMIR Mhealth Uhealth 2018; 6: e48.

126 Dacunto PJ, Klepeis NE, Cheng K-C, et al. Determining PM $_{2.5}$ calibration curves for a low-cost particle monitor: common indoor residential aerosols. Environ Sci Process Impacts 2015; 17: 1959-1966.

127 Nyarku M, Mazaheri M, Jayaratne R, et al. Mobile phones as monitors of personal exposure to air pollution: is this the future? PLoS One 2018; 13: e0193150.

128 Zimmerman N, Presto AA, Kumar SPN, et al. Closing the gap on lower cost air quality monitoring: machine learning calibration models to improve low-cost sensor performance. Atmospheric Meas Tech 2018; 11: 291-313.

129 Oltra C, Sala R, Boso À, et al. Public engagement on urban air pollution: an exploratory study of two interventions. Environ Monit Assess 2017; 189: 296.

130 Gordon SB, Bruce NG, Grigg J, et al. Respiratory risks from household air pollution in low and middle income countries. Lancet Respir Med 2014; 2: 823-860.

131 Lamichhane P, Sharma A, Mahal A. Impact of cleaner fuel use and improved stoves on acute respiratory infections: evidence from India. Int Health 2017; 9: 349-366.

132 Lewis JJ, Hollingsworth JW, Chartier RT, et al. Biogas stoves reduce firewood use, household air pollution, and hospital visits in Odisha, India. Environ Sci Technol 2017; 51: 560-569.

133 Yu K, Qiu G, Chan K-H, et al. Association of solid fuel use with risk of cardiovascular and all-cause mortality in rural China. JAMA 2018; 319: 1351-1361

134 Zhou Y, Zou Y, Li X, et al. Lung function and incidence of chronic obstructive pulmonary disease after improved cooking fuels and kitchen ventilation: a 9-year prospective cohort study. PLoS Med 2014; 11: e1001621.

135 Downward GS, van der Zwaag HP, Simons L, et al. Occupational exposure to indoor air pollution among bakery workers in Ethiopia; a comparison of electric and biomass cookstoves. Environ Pollut 2018; 233: 690-697.

136 Choi J-Y, Baumgartner J, Harnden S, et al. Increased risk of respiratory illness associated with kerosene fuel use among women and children in urban Bangalore, India. Occup Environ Med 2015; 72: 114-122. 
137 Buchner H, Rehfuess EA. Cooking and season as risk factors for acute lower respiratory infections in African children: a cross-sectional multi-country analysis. PLoS One 2015; 10: e0128933.

138 Langbein J. Firewood, smoke and respiratory diseases in developing countries-the neglected role of outdoor cooking. PLoS One 2017; 12: e0178631.

139 Grabow K, Still D, Bentson S. Test kitchen studies of indoor air pollution from biomass cookstoves. Energy Sustain Dev 2013; 17: 458-462.

140 Alexander D, Linnes JC, Bolton S, et al. Ventilated cookstoves associated with improvements in respiratory health-related quality of life in rural Bolivia. J Public Health 2014; 36: 460-466.

141 Accinelli RA, Llanos O, López LM, et al. Adherence to reduced-polluting biomass fuel stoves improves respiratory and sleep symptoms in children. BMC Pediatr 2014; 14: 12 .

142 Castañeda JL, Kheirandish-Gozal L, Gozal D, et al. Effect of reductions in biomass fuel exposure on symptoms of sleep apnea in children living in the Peruvian Andes: a preliminary field study: biomass and snoring in children. Pediatr Pulmonol 2013; 48: 996-999.

143 Das I, Pedit J, Handa S, et al. Household air pollution (HAP), microenvironment and child health: strategies for mitigating HAP exposure in urban Rwanda. Environ Res Lett 2018; 13: 045011.

144 Liu F, Zhao Y, Liu YQ, et al. Asthma and asthma related symptoms in 23,326 Chinese children in relation to indoor and outdoor environmental factors: the Seven Northeastern Cities (SNEC) Study. Sci Total Environ 2014 497-498: 10-17.

145 Kile ML, Coker ES, Smit E, et al. A cross-sectional study of the association between ventilation of gas stoves and chronic respiratory illness in U.S. children enrolled in NHANESIII. Environ Health 2014; 13: 71.

146 Jin $\mathrm{ZY}, \mathrm{Wu} \mathrm{M}$, Han RQ, et al. Household ventilation may reduce effects of indoor air pollutants for prevention of lung cancer: a case-control study in a Chinese population. PLoS One 2014; 9: e102685.

147 Seow WJ, Hu W, Vermeulen R, et al. Household air pollution and lung cancer in China: a review of studies in Xuanwei. Chin I Cancer 2014; 33: 471-475.

148 Salvi D, Limaye S, Muralidharan V, et al. Indoor particulate matter $<2.5 \mu \mathrm{m}$ in mean aerodynamic diameter and carbon monoxide levels during the burning of mosquito coils and their association with respiratory health. Chest 2016; 149: 459-466.

149 Holøs SB, Yang A, Lind M, et al. VOC emission rates in newly built and renovated buildings, and the influence of ventilation - a review and meta-analysis. Int J Ventilation 2019; 18: 153-166.

150 Balakrishnan K, Ghosh S, Ganguli B, et al. State and national household concentrations of PM2.5 from solid cookfuel use: results from measurements and modeling in India for estimation of the global burden of disease. Environ Health 2013; 12: 77.

151 Pope D, Bruce N, Dherani M, et al. Real-life effectiveness of 'improved' stoves and clean fuels in reducing $\mathrm{PM}_{25}$ and CO: systematic review and meta-analysis. Environ Int 2017; 101: 7-18.

152 Mortimer K, Ndamala CB, Naunje AW, et al. A cleaner burning biomass-fuelled cookstove intervention to prevent pneumonia in children under 5 years old in rural Malawi (the Cooking and Pneumonia Study): a cluster randomised controlled trial. Lancet 2017; 389: 167-175.

153 Muralidharan V, Sussan TE, Limaye S, et al. Field testing of alternative cookstove performance in a rural setting of western India. Int J Environ Res Public Health 2015; 12: 1773-1787.

154 Bruce N, Pope D, Rehfuess E, et al. WHO indoor air quality guidelines on household fuel combustion: strategy implications of new evidence on interventions and exposure-risk functions. Atmos Environ 2015; 106: 451-457.

155 Global Initiative for Chronic Obstructive Lung Disease. Global strategy for diagnosis, management and prevention of COPD. 2019. https://goldcopd.org/wp-content/uploads/2018/11/GOLD-2019-v1.5-FINAL-04Nov2018_ WMS.pdf Date last accessed: February 6, 2019.

156 Quansah R, Semple S, Ochieng CA, et al. Effectiveness of interventions to reduce household air pollution and/or improve health in homes using solid fuel in low-and-middle income countries: a systematic review and meta-analysis. Environ Int 2017; 103: 73-90.

157 Thakur M, Nuyts PAW, Boudewijns EA, et al. Impact of improved cookstoves on women's and child health in low and middle income countries: a systematic review and meta-analysis. Thorax 2018; 73: 1026-1040.

158 Noonan CW, Semmens EO, Smith P, et al. Randomized trial of interventions to improve childhood asthma in homes with wood-burning stoves. Environ Health Perspect 2017; 125: 097010

159 Guarnieri M, Diaz E, Pope D, et al. Lung function in rural Guatemalan women before and after a chimney stove intervention to reduce wood smoke exposure. Chest 2015; 148: 1184-1192.

160 Heinzerling AP, Guarnieri MJ, Mann JK, et al. Lung function in woodsmoke-exposed Guatemalan children following a chimney stove intervention. Thorax 2016; 71: 421-428.

161 Pilishvili T, Loo JD, Schrag S, et al. Effectiveness of six improved cookstoves in reducing household air pollution and their acceptability in rural Western Kenya. PLoS One 2016; 11: e0165529.

162 Gordon S, Mortimer K, Grigg J, et al. In control of ambient and household air pollution - how low should we go? Lancet Respir Med 2017; 5: 918-920.

163 Mortimer K, Balmes JR. Cookstove trials and tribulations: what is needed to decrease the burden of household air pollution? Ann Am Thorac Soc 2018; 15: 539-541.

164 Kabrein H, Yusof MZM, Leman AM. Progresses of filtration for removing particles and gases pollutants of indoor; limitations and future direction; review article. ARPN J Eng Appl Sci 2016; 11: 3633-3639.

165 US Environmental Protection Agency. Residential air cleaners. 2018. www.epa.gov/sites/production/files/ 2018-07/documents/residential_air_cleaners_-_a_technical_summary_3rd_edition.pdf Date last accessed: February 6, 2019.

166 Cui X, Li F, Xiang J, et al. Cardiopulmonary effects of overnight indoor air filtration in healthy non-smoking adults: a double-blind randomized crossover study. Environ Int 2018; 114: 27-36.

167 Kajbafzadeh M, Brauer M, Karlen B, et al. The impacts of traffic-related and woodsmoke particulate matter on measures of cardiovascular health: a HEPA filter intervention study. Occup Environ Med 2015; 72: 394-400.

168 Karottki DG, Spilak M, Frederiksen M, et al. An indoor air filtration study in homes of elderly: cardiovascular and respiratory effects of exposure to particulate matter. Environ Health 2013; 12: 116.

169 Park H-K, Cheng K-C, Tetteh AO, et al. Effectiveness of air purifier on health outcomes and indoor particles in homes of children with allergic diseases in Fresno, California: a pilot study. J Asthma 2017; 54: 341-346. 
Shao D, Du Y, Liu S, et al. Cardiorespiratory responses of air filtration: a randomized crossover intervention trial in seniors living in Beijing. Sci Total Environ 2017; 603-604: 541-549.

Barn P, Gombojav E, Ochir C, et al. The effect of portable HEPA filter air cleaners on indoor $\mathrm{PM}_{2.5}$ concentrations and second hand tobacco smoke exposure among pregnant women in Ulaanbaatar, Mongolia: the UGAAR randomized controlled trial. Sci Total Environ 2018; 615: 1379-1389.

Fisk WJ, Chan WR. Health benefits and costs of filtration interventions that reduce indoor exposure to PM2.5 during wildfires. Indoor Air 2017; 27: 191-204.

Aldred JR, Darling E, Morrison G, et al. Benefit-cost analysis of commercially available activated carbon filters for indoor ozone removal in single-family homes. Indoor Air 2016; 26: 501-512.

US Environmental Protection Agency. Wildfire smoke. A guide for public health officials. 2016. www3.epa.gov/ airnow/wildfire_may2016.pdf Date last accessed: February 6, 2019.

Elliott C. Guidance for BC public health decision makers during wildfire smoke events. 2014. www.bccdc.ca/ resource-gallery/Documents/Guidelines\%20and\%20Forms/Guidelines\%20and\%20Manuals/Health-Environment/ WFSG_BC_guidance_2014_09_03trs.pdf Date last accessed: February 6, 2019.

Fisk WJ. Health benefits of particle filtration. Indoor Air 2013; 23: 357-368.

Chen R, Zhao A, Chen $\mathrm{H}$, et al. Cardiopulmonary benefits of reducing indoor particles of outdoor origin. $J \mathrm{Am}$ Coll Cardiol 2015; 65: 2279-2287.

Butz AM. A randomized trial of air cleaners and a health coach to improve indoor air quality for inner-city children with asthma and secondhand smoke exposure. Arch Pediatr Adolesc Med 2011; 165: 741-748.

Peng RD, Butz AM, Hackstadt AJ, et al. Estimating the health benefit of reducing indoor air pollution in a randomized environmental intervention. J R Stat Soc Ser A Stat Soc 2015; 178: 425-443.

Hackstadt AJ, Matsui EC, Williams DAL, et al. Inference for environmental intervention studies using principal stratification. Stat Med 2014; 33: 4919-4933.

ja-Ying L, Zhao C, Jia-Jun G, et al. Efficacy of air purifier therapy in allergic rhinitis. Asian Pac J Allergy Immunol 2018; 36: 217-221.

Paulin LM, Diette GB, Scott M, et al. Home interventions are effective at decreasing indoor nitrogen dioxide concentrations. Indoor Air 2014; 24: 416-424. in a population of car commuters. Epidemiology 2015; 26: 546-555. symptoms in children with asthma and healthy children in western Japan. J Asthma 2018; 55: 712-719.

Rider CF, Carlsten C. Air pollution and resistance to inhaled glucocorticoids: evidence, mechanisms and gaps to fill. Pharmacol Ther 2019; 194: 1-21.

Maikawa CL, Weichenthal S, Wheeler AJ, et al. Particulate oxidative burden as a predictor of exhaled nitric oxide in children with asthma. Environ Health Perspect 2016; 124: 1616-1622.

Ierodiakonou D, Zanobetti A, Coull BA, et al. Ambient air pollution, lung function, and airway responsiveness in asthmatic children. J Allergy Clin Immunol 2016; 137: 390-399.

Miyata R, Bai N, Vincent R, et al. Statins reduce ambient particulate matter-induced lung inflammation by promoting the clearance of particulate matter $<10 \mu \mathrm{m}$ from lung tissues. Chest 2013; 143: 452-460.

Cosselman KE, Navas-Acien A, Kaufman JD. Environmental factors in cardiovascular disease. Nat Rev Cardio 2015; 12: 627-642.

Péter S, Holguin F, Wood L, et al. Nutritional solutions to reduce risks of negative health impacts of air pollution. Nutrients 2015; 7: 10398-10416.

Guilleminault L, Williams E, Scott H, et al. Diet and asthma: is it time to adapt our message? Nutrients 2017; 9: 1227. Whyand T, Hurst JR, Beckles M, et al. Pollution and respiratory disease: can diet or supplements help? A review. Respir Res 2018; 19: 79.

Barchitta M, Maugeri A, Quattrocchi A, et al. Mediterranean diet and particulate matter exposure are associated with LINE-1 methylation: results from a cross-sectional study in women. Front Genet 2018; 9: 514.

Hansell AL, Bakolis I, Cowie CT, et al. Childhood fish oil supplementation modifies associations between traffic related air pollution and allergic sensitisation. Environ Health 2018; 17: 27.

Egner PA, Chen JG, Zarth AT, et al. Rapid and sustainable detoxication of airborne pollutants by broccoli sprout beverage: results of a randomized clinical trial in China. Cancer Prev Res 2014; 7: 813-823.

Heber D, Li Z, Garcia-Lloret M, et al. Sulforaphane-rich broccoli sprout extract attenuates nasal allergic response to diesel exhaust particles. Food Funct 2014; 5: 35-41.

Carlsten C, MacNutt MJ, Zhang Z, et al. Anti-oxidant $N$-acetylcysteine diminishes diesel exhaust-induced increased airway responsiveness in person with airway hyper-reactivity. Toxicol Sci 2014; 139: 479-487.

Sack CS, Jansen KL, Cosselman KE, et al. Pretreatment with antioxidants augments the acute arterial vasoconstriction caused by diesel exhaust inhalation. Am J Respir Crit Care Med 2016; 193: 1000-1007.

Tong H. Dietary and pharmacological intervention to mitigate the cardiopulmonary effects of air pollution toxicity. Biochim Biophys Acta 2016; 1860: 2891-2898.

O'Callaghan-Gordo C, Fthenou E, Pedersen M, et al. Outdoor air pollution exposures and micronuclei frequencies in lymphocytes from pregnant women and newborns in Crete, Greece (Rhea cohort). Environ Res 2015; 143: 170-176.

Ban J, Zhou L, Zhang Y, et al. The health policy implications of individual adaptive behavior responses to smog pollution in urban China. Environ Int 2017; 106: 144-152.

Li X, Huang S, Jiao A, et al. Association between ambient fine particulate matter and preterm birth or term low birth weight: an updated systematic review and meta-analysis. Environ Pollut 2017; 227: 596-605.

Burns J, Boogaard H, Polus S, et al. Interventions to reduce ambient particulate matter air pollution and their effect on health. Cochrane Database Syst Rev 2019; 5: CD010919.

Central Pollution Control Board, Ministry of Environment, Forest and Climate Change, Government of India. National Air Quality Index. 2019. https://app.cpcbccr.com/AQI_India Date last accessed: February 4, 2019.

NASA. Air quality. 2019. https://earthdata.nasa.gov/earth-observation-data/near-real-time/hazards-and-disasters/ air-quality Date last accessed: February 4, 2019.

London Air Quality Network. London air. 2019. www.londonair.org.uk/LondonAir/Default.aspx Date last accessed: February 4, 2019. 